\title{
Structures and Functions of the $3^{\prime}$ Untranslated Regions of Positive-Sense Single-Stranded RNA Viruses Infecting Humans and Animals
}

\section{OPEN ACCESS}

Edited by:

Jean-Christophe Paillart,

Université de Strasbourg, France

Reviewed by:

Damien Ferhadian,

National Institutes of Health (NIH),

United States

Ricardo Soto-Rifo,

University of Chile, Chile

*Correspondence:

Anchun Cheng

chenganchun@vip.163.com

tThese authors have contributed equally to this work and share first authorship

Specialty section:

This article was submitted to Virus and Host,

a section of the journal Frontiers in Cellular and Infection Microbiology

Received: 20 May 2020

Accepted: 23 July 2020 Published: 27 August 2020

Citation: Liu Y, Zhang Y, Wang M, Cheng A, Yang $Q$, Wu Y, Jia R, Liu M, Zhu D, Chen S, Zhang S, Zhao $X$, Huang J, Mao S, Ou X, Gao Q, Wang Y, Xu Z,

Chen Z, Zhu L, Luo Q, Liu Y, Yu Y,

Zhang L, Tian B, Pan L and Chen $X$ (2020) Structures and Functions of the

3' Untranslated Regions of

Positive-Sense Single-Stranded RNA

Viruses Infecting Humans and

Animals.

Front. Cell. Infect. Microbiol. 10:453. doi: 10.3389/fcimb.2020.00453

\begin{abstract}
Yuanzhi Liu ${ }^{1,2,3 \dagger}$, Yu Zhang ${ }^{1,2 \dagger}$, Mingshu Wang 1,2,3†, Anchun Cheng ${ }^{1,2,3 *}$, Qiao Yang ${ }^{1,2,3}$, Ying Wu ${ }^{1,2,3}$, Renyong Jia ${ }^{1,2,3}$, Mafeng Liu ${ }^{1,2,3}$, Dekang Zhu ${ }^{2,3}$, Shun Chen ${ }^{1,2,3}$, Shaqiu Zhang ${ }^{1,2,3}$, XinXin Zhao ${ }^{1,2,3}$, Juan Huang ${ }^{1,2,3}$, Sai Mao ${ }^{1,2,3}$, Xumin Ou ${ }^{1,2,3}$, Qun Gao ${ }^{1,2,3}$, Yin Wang ${ }^{2}$, Zhiwen $X u^{2}$, Zhengli Chen ${ }^{2}$, Ling Zhu ${ }^{2}$, Qihui Luo ${ }^{2}$, Yunya Liu ${ }^{1,2,3}$, Yanling Yu ${ }^{1,2,3}$, Ling Zhang ${ }^{1,2,3}$, Bin Tian ${ }^{1,3}$, Leichang Pan $^{1,3}$ and Xiaoyue Chen ${ }^{1,2,3}$

${ }^{1}$ Institute of Preventive Veterinary Medicine, Sichuan Agricultural University, Chengdu, China, ${ }^{2}$ Key Laboratory of Animal Disease and Human Health of Sichuan Province, Sichuan Agricultural University, Chengdu, China, ${ }^{3}$ Research Center of Avian Disease, College of Veterinary Medicine, Sichuan Agricultural University, Chengdu, China
\end{abstract}

The $3^{\prime}$ untranslated region ( $3^{\prime}$ UTR) of positive-sense single-stranded RNA [ssRNA(+)] viruses is highly structured. Multiple elements in the region interact with other nucleotides and proteins of viral and cellular origin to regulate various aspects of the virus life cycle such as replication, translation, and the host-cell response. This review attempts to summarize the primary and higher order structures identified in the $3^{\prime}$ UTR of $\operatorname{ssRNA}(+)$ viruses and their functional roles.

Keywords: 3' UTR, structures, functions, ssRNA(+), viruses

\section{INTRODUCTION}

Positive-sense single-stranded RNA [ssRNA(+)] viruses consist of 56 families according to the current ICTV (International Committee on Taxonomy of Viruses) Report on Virus Taxonomy (International Committee on Taxonomy of Viruses, 2019). The genomic RNAs of all ssRNA(+) viruses function as mRNAs and are directly translated to produce one or more polyproteins. A typical ssRNA $(+)$ virus genomic RNA is comprised of a $5^{\prime}$ untranslated region $\left(5^{\prime}\right.$ UTR), one or more open reading frames (ORFs) and a $3^{\prime}$ UTR. For most ssRNA(+) viruses, the $5^{\prime}$-terminus of the genomic RNA is covalently linked to a small VPg protein or a protein equivalent to VPg or a cap structure, and the $3^{\prime}$-terminus is polyadenylated or the $3^{\prime}$ UTR contains poly(A/U) regions, similar to the polyadenylation signal (Figure 1).

Once a ssRNA(+) virus invaded a host cell, its RNA will first attach to the host ribosome and be translated to produce one or more polyproteins, which will be rapidly cleaved by viral and/or cellular enzymes to generate several structural and non-structural proteins that participate in assembling complete virus particles. RNA-dependent RNA polymerase (RdRP), a virus encoded non-structural protein, synthesizes negative-strand RNAs using viral positive-strand RNAs as templates. Subsequently, more positive-stranded RNAs will be synthesized by RdRP using negativestrand RNAs as templates. However, for viruses of the order Nidovirales, both the synthesis of positive-stranded genomic RNAs and the transcription of subgenomic mRNA (sg mRNA) are required for viral replication. The sg mRNA contains same $5^{\prime}$ and $3^{\prime}$-termini and will be translated to produce different structural proteins (Pasternak et al., 2006; Cao et al., 2012, 2013, 2016; Sun et al., 2016, 2017; Ou et al., 2017, 2018; Lai et al., 2019; Wen et al., 2019). 


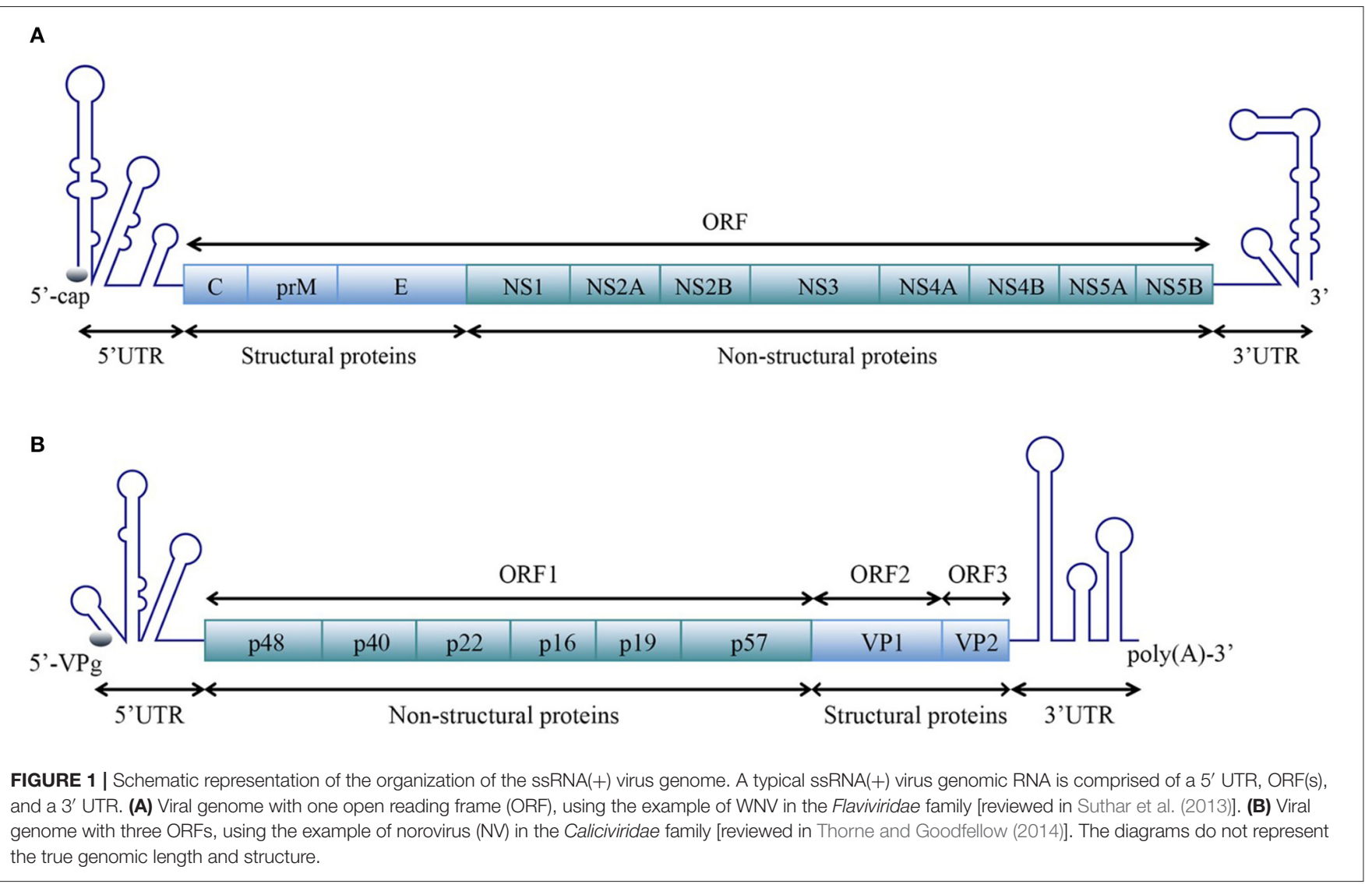

Both the synthesis of negative-strand RNA and the translation of viral polyproteins use positive-strand RNA as a template. How to reasonably convert these two processes is a problem encountered by all ssRNA(+) viruses. Taking poliovirus as an example, poly(rC)-binding protein 2 (PCBP2) is required for both IRES-dependent translation and RNA replication. When performing IRES-dependent translation, PCBP2 interacts with the IRES element and recruits ribosomes to viral RNA, then the ribosomes that move from $5^{\prime}$ to $3^{\prime}$ block RdRP $3 \mathrm{D}$ that synthesizes negative stranded RNA from $3^{\prime}$ to $5^{\prime}$. As the viral protease $3 \mathrm{C} / 3 \mathrm{CD}$ accumulates, $\mathrm{PCBP} 2$ is cleaved by $3 \mathrm{C} / 3 \mathrm{CD}$, which blocks the recruitment of ribosomes to the IRES element. At this time, RdRP 3D can successfully pass through the RNA and synthesize negative-strand RNA from $3^{\prime}$ to $5^{\prime}$ (Perera et al., 2007).

Similar to the $3^{\prime}$ UTR of the mature eukaryotic mRNA, the $3^{\prime}$ UTR of the ssRNA(+) virus genomic RNA possess multiple functional primary and higher order structures. These structures have been predicted through bioinformatics analyses and validated experimentally. Although the nucleotide sequences of the $3^{\prime}$ UTR from viruses of same species differ between strains, their higher order structures are generally conserved. Nucleotides and proteins from the virus and host directly or indirectly interact with structural elements in $3^{\prime}$ UTRs, participating in regulating the cyclization, replication, and translation of viral genomic RNA (Tables 1, 2); studies of the structure and function of the $3^{\prime}$ UTRs of ssRNA $(+)$ viruses are important for clarifying the detailed mechanism of the viral life cycle and anti-viral research.

\section{PRIMARY STRUCTURES AND FUNCTIONS}

Primary structures, or nucleotide sequences, are the basis for the formation of specific higher-order structures. For ssRNA(+) viruses, their genomic RNAs contain several functional sequences, which directly participate in viral genome cyclization, replication, and translation and have important functions in the viral life cycle.

\section{Cyclization Sequences and Genome Cyclization of Flaviviruses}

For members of the Flavivirus genus in the Flaviviridae family, replication of genomic RNAs includes the cyclization process. A long-range RNA-RNA interaction occurs when a short sequence of the $3^{\prime}$ UTR complements with another short sequence of the $5^{\prime}$ UTR and the $5^{\prime}$ UTR' s contiguous upstream, which cyclizes the genomic RNA [reviewed in Nicholson and White (2014)]. Genome cyclization has been observed with atomic force microscopy (AFM) (Figures 2C,D).

The $3^{\prime}$ UTR in the flavivirus genome possess a stem-loop termed the $3^{\prime}$ SL containing conserved sequence 1 (CS1) in which an 8 nt-long $3^{\prime}$ cyclization sequence ( $3^{\prime}$ CYC) is located (Hahn et al., 1987). The $3^{\prime}$ CYC complementarily binds to a $5^{\prime}$ CYC located in the capsid protein coding region (Figure 3 ). Research into dengue virus (DENV), West Nile virus (WNV) and tick-borne encephalitis virus (TBEV) has shown that the interaction between the $3^{\prime} \mathrm{CYC}$ and $5^{\prime} \mathrm{CYC}$ and several base 
TABLE 1 | Cellular proteins that interact with the $3^{\prime}$ UTRs of SSRNA(+) viruses.

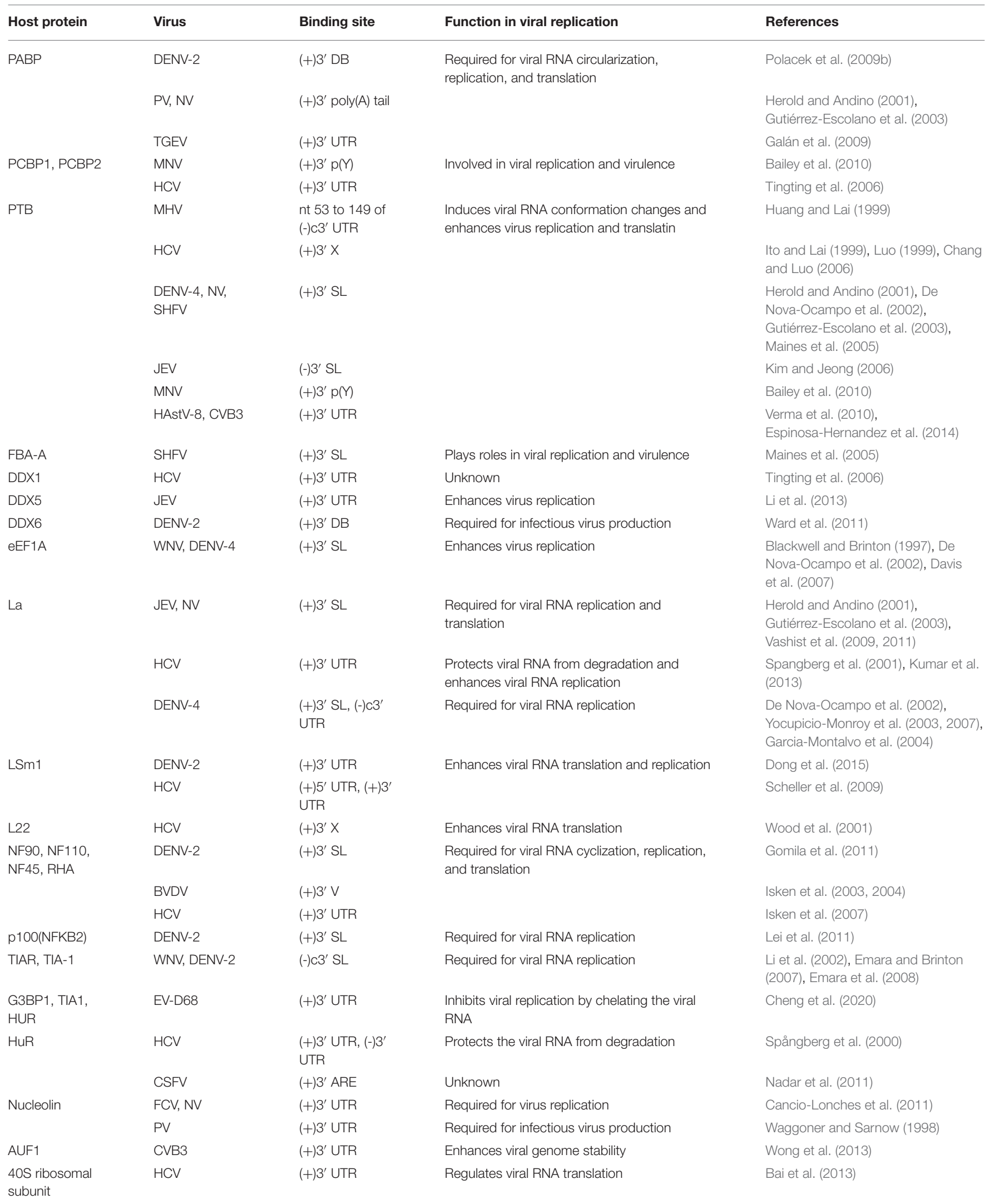


TABLE 1 | Continued

\begin{tabular}{|c|c|c|c|c|}
\hline Host protein & Virus & Binding site & Function in viral replication & References \\
\hline hnRNPA1 & $\mathrm{MHV}$ & $(+) 3^{\prime}$ UTR & Mediates potential 5'-3'-end cross-talk & Huang and Lai (2001) \\
\hline hnRNPA2 & JEV & $(-) c 3^{\prime}$ UTR & Required for viral RNA replication & Katoh et al. (2011) \\
\hline hnRNPC & $\mathrm{HCV}$ & $\begin{array}{l}(+) 3^{\prime} \text { UTR, }(-) 3^{\prime} \\
\text { UTR }\end{array}$ & Protects the viral RNA from degradation & Spångberg et al. (2000) \\
\hline hnRNPE2 & $\mathrm{HCV}$ & $(+) 3^{\prime}$ UTR & Unknown & Tingting et al. (2006) \\
\hline hnRNPQ & TGEV & $(+) 3^{\prime}$ UTR & Enhances viral RNA replication & Galán et al. (2009) \\
\hline EPRS & TGEV & $(+) 3^{\prime}$ UTR & Enhances viral RNA replication & Galán et al. (2009) \\
\hline Mov34 & JEV & $(+) 3^{\prime} \mathrm{SL}$ & May play roles in viral RNA replication & Ta and Vrati (2000) \\
\hline m-aconitase & $\mathrm{MHV}$ & $(+) 3^{\prime}$ UTR & Unknown & $\begin{array}{l}\text { Nanda and Leibowitz (2001), Nanda } \\
\text { et al. (2004) }\end{array}$ \\
\hline FBP1 & JEV & $(+) 3^{\prime}$ UTR & Inhibits the translation of viral RNAs & Chien et al. (2011) \\
\hline \multirow{2}{*}{$\begin{array}{l}\text { G3BP1, G3BP2, } \\
\text { CAPRIN1 }\end{array}$} & DENV-2 & $(+) 3^{\prime} \mathrm{VR}$ & Relevant to virus replication and pathogenesis & Bidet et al. (2014) \\
\hline & $\mathrm{HCV}$ & $(+) 3^{\prime}$ UTR & Regulates virus replication & Tingting et al. (2006) \\
\hline GAPDH & TGEV & $(+) 3^{\prime}$ UTR & Inhibits viral RNA replication & Galán et al. (2009) \\
\hline YBX1 & DENV-2 & $(+) 3^{\prime} \mathrm{SL}$ & Inhibits viral RNA translation & Paranjape and Harris (2007) \\
\hline MCPIP1 & DENV-2, JEV & $(+) 3^{\prime}$ UTR & Degrades viral RNAs & Lin et al. (2013) \\
\hline
\end{tabular}

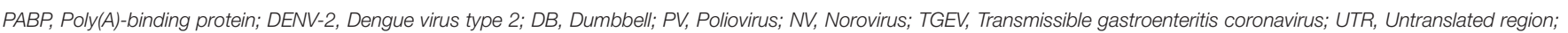

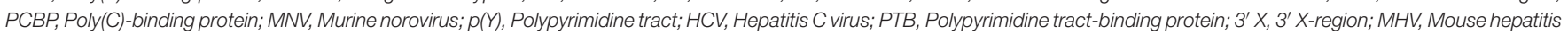

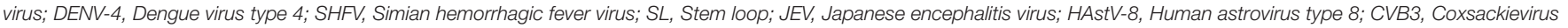

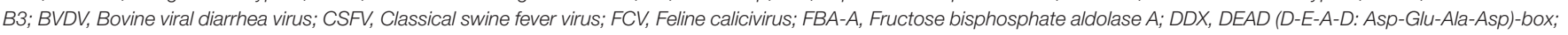

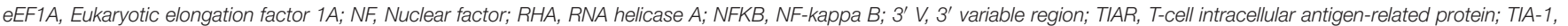

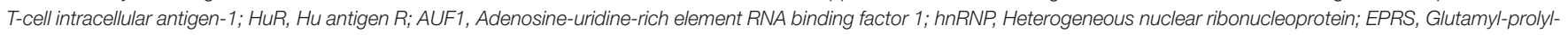

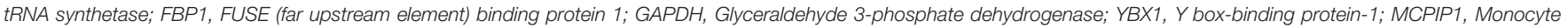
chemoattractant protein 1-induced protein 1.

TABLE 2 | Viral proteins that interact with the $3^{\prime}$ UTRs of ssRNA(+) viruses.

\begin{tabular}{|c|c|c|c|c|}
\hline Virus protein & Virus & Binding site & Function in viral replication & References \\
\hline $\mathrm{CP}$ & $\mathrm{HCV}$ & $(+) 3^{\prime} \mathrm{SL}$ & Unknown & Yu et al. (2009) \\
\hline 3D & EMCV & $(+) 3^{\prime}$ UTR & Initiates viral RNA synthesis & Cui et al. (1993) \\
\hline NS5A, NS5B & CSFV & $(+) 3^{\prime}$ SL1, (+)3' SL2, (-)3' UTR & Regulates viral RNA replication & $\begin{array}{l}\text { Sheng et al. (2007, 2012), Chen et al. } \\
\text { (2012) }\end{array}$ \\
\hline NS5A & $\mathrm{HCV}$ & polyU/UC & Inhibits viral RNA translation & Hoffman et al. (2015) \\
\hline Nucleocapsid & IBV & $(+) 3^{\prime}$ UTR & Unknown & Collisson et al. (2001) \\
\hline \multirow[t]{2}{*}{ NS2A } & KUNV & $(+) 3^{\prime}$ UTR & Unknown & Mackenzie et al. (1998) \\
\hline & DENV-2 & pk3, pk4, and $3^{\prime} S L$ of $(+) 3^{\prime}$ UTR & The signal to recruit viral RNA to the virion assembly site & Xie et al. (2019) \\
\hline
\end{tabular}

CP, Core protein; EMCV, Encephalomyocarditis virus; NS5A, Non-structural proteins 5A; NS5B, Non-structural proteins 5B; KUNV, Kunjin virus.

sites among them are required for viral RNA replication, and the precise and specific sequences determine the function of the CYC, but not the secondary structure and complementary relationship between base sites (Kofler et al., 2006; Suzuki et al., 2008; Basu and Brinton, 2011; Manzano et al., 2011). However, the $5^{\prime}$ CYC-3' CYC interaction of DENV does not participate in viral translation (Holden et al., 2006). In addition to the $5^{\prime} \mathrm{CYC} / 3^{\prime}$ CYC, the upstream AUG region (UAR) and downstream AUG region (DAR) also function as cyclization sequences involved in viral RNA cyclization. The $5^{\prime}$ UAR is located in immediately upstream of the start codon AUG, while the $3^{\prime}$ UAR is located at the bottom of the $3^{\prime} \mathrm{SL}$ (Figure 3). The $5^{\prime}$ UAR- $3^{\prime}$ UAR complementary relationship, which is stabilized by the $5^{\prime}$ CYC$3^{\prime}$ CYC interaction (Polacek et al., 2009a), is necessary for viral replication. Similarly, the $5^{\prime} \mathrm{UAR} / 3^{\prime} \mathrm{UAR}$ interaction rarely affects viral translation (Zhang et al., 2008). The $5^{\prime}$ DAR is located immediately downstream of the start codon AUG, and the $3^{\prime}$ DAR is located at the bottom of the hairpin stem-loop termed HP- $3^{\prime}$ SL (Figure 3). The interaction between the $5^{\prime}$ DAR and $3^{\prime}$ DAR is involved in viral RdRP reactivity and RNA replication efficiency (Friebe et al., 2011), but further studies are needed to determine whether they are also irrelevant to translation.

The $5^{\prime} \mathrm{CYC} / 3^{\prime} \mathrm{CYC}, 5^{\prime} \mathrm{UAR} / 3^{\prime} \mathrm{UAR}$, and $5^{\prime} \mathrm{DAR} / 3^{\prime} \mathrm{DAR}$ form several base pairs within the flavivirus genome that enable the linear genomic RNA to transform to a cyclized form. According to a phylogenetic analysis, the cyclization sequences are highly conserved among mosquito-borne flavivirus genomes (Zhang et al., 2008), indicating that the long-range RNA-RNA 
A

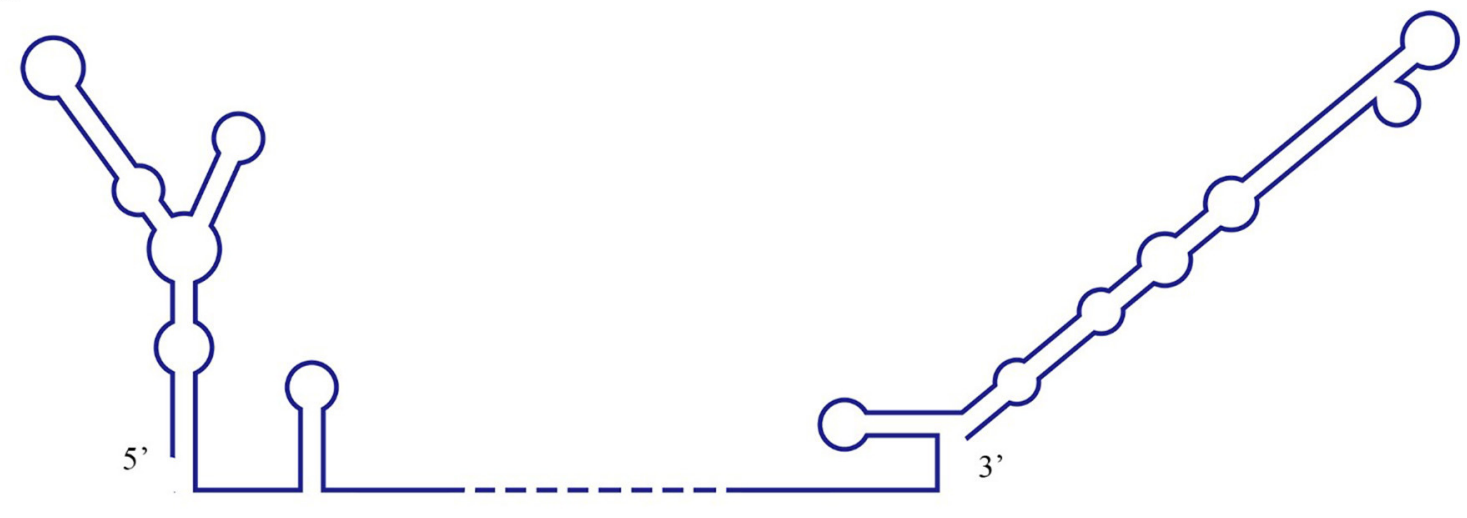

C

B
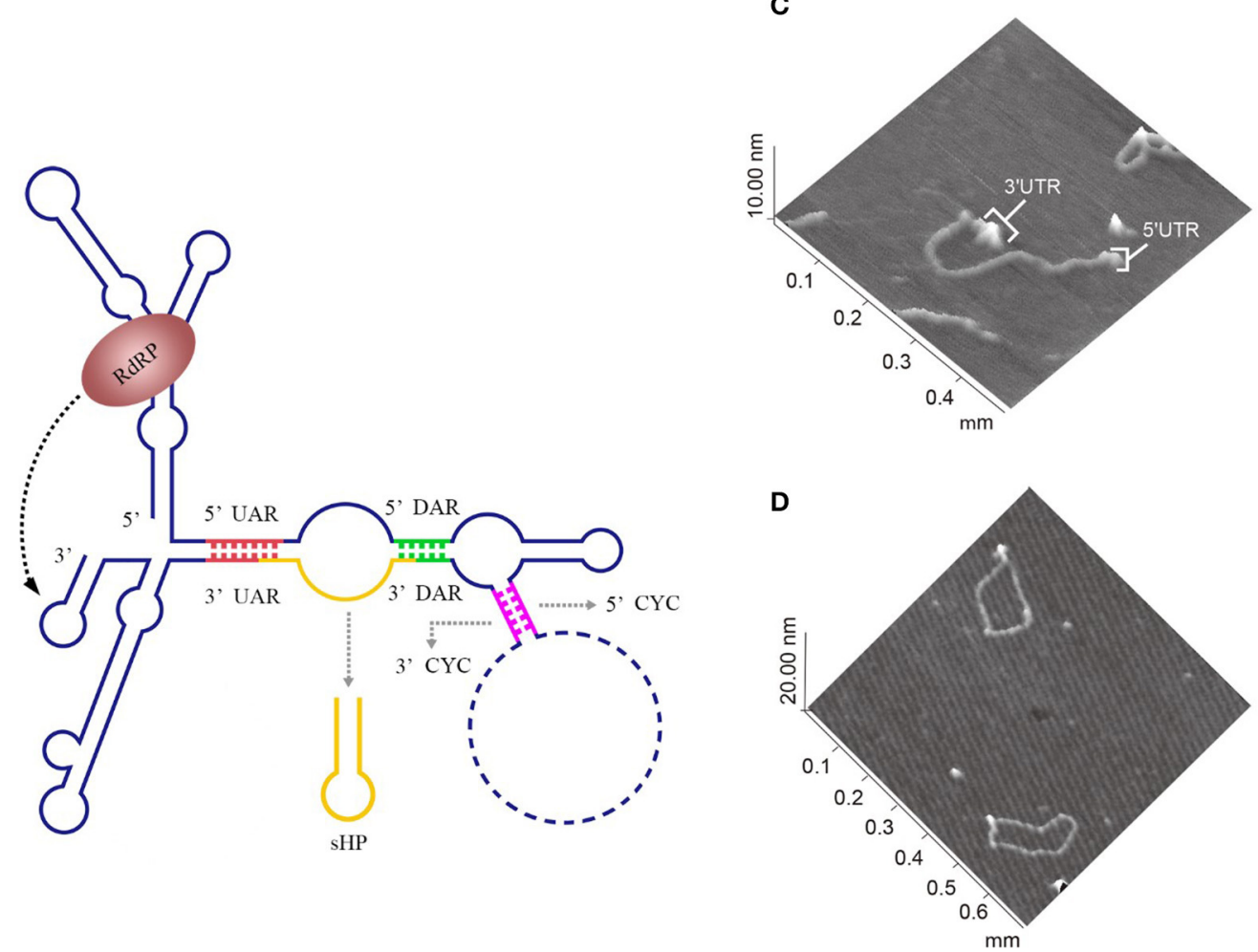

FIGURE 2 | Circularization of the DENV genome. (A) The linear form of the DENV genomic RNA. When the interactions between the $3^{\prime}$ and $5^{\prime} c y c l i z a t i o n ~ s e q u e n c e s$ are not considered, the DENV genome appears in a linear form (Villordo and Gamarnik, 2009). (B) The circularized form of the DENV genomic RNA. 5' CYC/3' CYC, 5' UAR/3' UAR, and 5' DAR/3' DAR bind complementarily and cyclize the DENV genome, reducing the distance between the $5^{\prime}$ and $3^{\prime}$ ends and exposing the $3^{\prime}$-terminal nucleotides, which are indispensable for RdRP to recognize the $3^{\prime}$-terminus and initiate negative-strand synthesis [reviewed in Nicholson and White (2014)]. (C) Visualization of the model RNA molecules using AFM. A single RNA molecule is shown in a linear conformation. The double-stranded RNA region is flanked by single-stranded regions corresponding to the $5^{\prime}$ UTR and $3^{\prime}$ UTR of dengue virus. (D) Image of individual RNA molecules in the circular conformation. Contacts between the $5^{\prime}$ and $3^{\prime}$ single-stranded regions of the molecules are observed. The images shown in (C) and (D) were excerpted from a previous study (Alvarez et al., 2005) after obtaining the authors' permission. Figures have been approved by the original author and obtained the licenses through Rights Licensing Expert (www.copyright.com), the license numbers were, respectively 4045761041172 (for A,B) 4040580733464 (for C,D).

interactions between the $5^{\prime}$ UTR and $3^{\prime}$ UTR are very likely the common mechanism of flavivirus genome cyclization. In addition, DENV RdRP binds a stem-loop SLA in the $5^{\prime}$ UTR of the genome and facilitates viral replication by forming interactions between the cyclization sequences of $5^{\prime}$ UTR and 3' UTR (Filomatori et al., 2006; Dong et al., 2007). Thus, the binding of RdRP to SLA, and the complementary pairing between cyclization sequences may have some connection in the replication of DENV RNA. A relatively complete and rational model was established to explain the balance between circular and linear forms of the DENV genome and the initiation of RNA synthesis by RdRP (Villordo and Gamarnik, 2009) 
(Figures 2A,B). In this model, $5^{\prime} \mathrm{CYC} / 3^{\prime} \mathrm{CYC}, 5^{\prime} \mathrm{UAR} / 3^{\prime} \mathrm{UAR}$, and $5^{\prime} \mathrm{DAR} / 3^{\prime}$ DAR complement and cyclize the DENV genome, shortening the distance between $5^{\prime}$ and $3^{\prime}$ ends and exposing the $3^{\prime}$-terminal nucleotides. Once RdRP binds to SLA, its position will be near the $3^{\prime}$-terminus, which allows the RdRP to recognize the $3^{\prime}$-terminus and initiate negative-strand synthesis. Moreover, the WNV $3^{\prime}$ UAR could alternate between pairing with $5^{\prime}$ UAR or with the local $3^{\prime}$ end (Zhang et al., 2008) and RdRP binds to the $5^{\prime}$ DAR (Dong et al., 2008), which may be also involved in cyclizing the viral genome. The flaviviral genome cyclization mechanism and the initiation of the negative-strand synthesis have been extensively studied; however, the synthesis of positive-strand RNAs from negative-strand RNAs is still poorly understood and more information is needed to elucidate the complete mechanism of cyclization and synthesis of the flavivirus genome.

\section{Other Specific Sequences With Important Functions}

A conserved $5^{\prime}$-CACAG- $3^{\prime}$ pentanucleotide $(\mathrm{PN})$ located in the $3^{\prime} \mathrm{SL}$ of the flavivirus $3^{\prime}$ UTR (Figure 3) is required for viral replication, but not translation (Khromykh et al., 2003; Elghonemy et al., 2005; Tilgner et al., 2005). However, only the $\mathrm{G}$ in the $5^{\prime}$-CACAG-3' sequence is required for yellow fever virus (YFV) replication (Silva et al., 2007). In addition to this $\mathrm{PN}$, a conserved $5^{\prime}$-ACAGUGC-3' sequence in the flavivirus $3^{\prime}$ SL may be involved in formation of the viral replication complex and plays a role in viral replication (Khromykh et al., 2003; Elghonemy et al., 2005). The specific 5' -CACAG-3' and 5' ACAGUGC- $3^{\prime}$ nucleotides may interact with other sequences or proteins of the virus to regulate viral replication, but additional in-depth studies are required.

Research examining the Japanese encephalitis virus (JEV), Kunjin virus (KUNV), WNV, DENV, and YFV has revealed multiple conserved sequences in the flaviviral $3^{\prime}$ UTR, including conserved sequence 1 (CS1), CS2, CS3 and repeat conserved sequence 2 (RCS2), RCS3 (Figure 3); these sequences are required for efficient viral replication and translation (Hahn et al., 1987; Khromykh and Westaway, 1997; Wei et al., 2009).

\section{HIGH-ORDER STRUCTURES AND FUNCTIONS}

\section{Stem-Loop Structures}

Stem-loop structures consist of stem regions and loop regions and are widely present in the secondary structures of singlestranded RNA. The stem is the double-stranded region formed by base pairings between the reverse complementary sequence, and the loop is the single-stranded region formed by unpaired bases. By interacting with viral and host proteins, stem-loop structures regulate viral replication and translation and are multifunctional and important for adjusting the life activities of the virus and host, as shown in Table 1. Here, the widely studied stem-loop structures and the corresponding functions are discussed with their interacting proteins.

The La protein binds to the $3^{\prime}$ UTRs of most members of the Flaviviridae family (Herold and Andino, 2001; Spangberg et al., 2001; De Nova-Ocampo et al., 2002; Garcia-Montalvo et al., 2004; Vashist et al., 2009). The binding site for La in the DENV-4 3' UTR are located in the area between CS1 and 3' SL (De Nova-Ocampo et al., 2002). Additionally, La binds to the DENV-encoded non-structural proteins NS3 and NS5 (GarciaMontalvo et al., 2004), which possess protease and RdRP activity, respectively. Interestingly, the binding of the La protein from mosquito cells to $3^{\prime}$ UTRs of the positive- and negative-strand of DENV-4 inhibits the synthesis of the positive- and negativestrand of the genome (Yocupicio-Monroy et al., 2007). This may be related to the adaptability of the host. La proteins from human and mosquitoe may have different ability to regulate viral replication. La protein from mosquitoe may control the viral load in its body, making it better as a vector to infect human. Moreover, the binding of La to HCV $3^{\prime}$ UTR protects the $3^{\prime}$ UTR from degradation by the cytoplasmic RNase and mediates the circularization of HCV genome and viral replication, which are enhanced by the interaction between HuR and La (Spangberg et al., 2001; Shwetha et al., 2015). La also binds to a $5^{\prime}$-GCAC$3^{\prime}$ sequence in the HCV $5^{\prime} \mathrm{UTR}$, and mutation of $5^{\prime}$-GCAC- $3^{\prime}$ influences the binding of La to viral RdRP NS5B and inhibits viral replication, but translation is not affected (Kumar et al., 2013). Thus, a model was proposed to explain the functions of $\mathrm{La}$ and the $5^{\prime}$-GCAC- $3^{\prime}$ sequence in HCV replication (Kumar et al., 2013). NS5 and $3^{\prime}$ UTR form a virus replication complex, and La binding with NS5 and $5^{\prime}$-GCAC- $3^{\prime}$ brings the $5^{\prime}$ UTR closer to the $3^{\prime}$ UTR (Figure 4). Interestingly, a cyclized conformation of the HCV genome is observed in this model, which resembles the genome cyclization strategy used by poliovirus (PV). The PV RdRP containing the precursor protein $3 \mathrm{CD}$ and the cellular factor PCBP bind to the $5^{\prime}$ UTR cloverleaf, and the cellular factor poly(A)-binding protein (PABP) binds to the $3^{\prime} \mathrm{UTR}$. Interactions between $3 \mathrm{D}, \mathrm{PCBP}$, and PABP hold the $5^{\prime}$ and the $3^{\prime}$ ends of the PV RNA in a non-covalent juxtaposition that leads to the circularization of the genomic RNA. These interactions bring the viral RdRP (3D protein) in close proximity to the $3^{\prime}$ poly(A) tail and enable the initiation of negative-strand RNA synthesis (Herold and Andino, 2001) (Figure 5). Furthermore, transcription factor NF90 also participates in cyclizing the HCV and bovine viral diarrhea virus (BVDV) genome (Isken et al., 2003). Thus, in addition to long-range RNA-RNA interactions, protein-protein and protein-RNA interactions are also relevant to viral genome cyclization.

The genomic $3^{\prime}$ UTR of ssRNA(+) virus usually contains one or more polyadenylated regions, which have been widely reported to interact with the cellular polypyrimidine tractbinding protein (PTB). PTB binds to $3^{\prime}$ SL of HCV (Ito and Lai, 1999; Luo, 1999; Chang and Luo, 2006), DENV4 (De NovaOcampo et al., 2002), simian hemorrhagic fever virus (SHFV) (Maines et al., 2005) and mouse hepatitis virus (MHV) (Huang and Lai, 1999), to the NV (Gutiérrez-Escolano et al., 2003) positive-strand RNA and to the $3^{\prime}$ SL of the JEV (Kim and Jeong, 2006) negative-strand RNA. Mutation of the PTB binding site in the CVB3 3' UTR reduces viral translation, indicating that PTB is involved in CVB3 translation (Verma et al., 2010). According to a similar study, the binding of $\mathrm{PTB}$ to the $\mathrm{HCV} 3^{\prime} \mathrm{X}$ region in the $3^{\prime}$ UTR may stimulate viral replication and translation (Brocard 


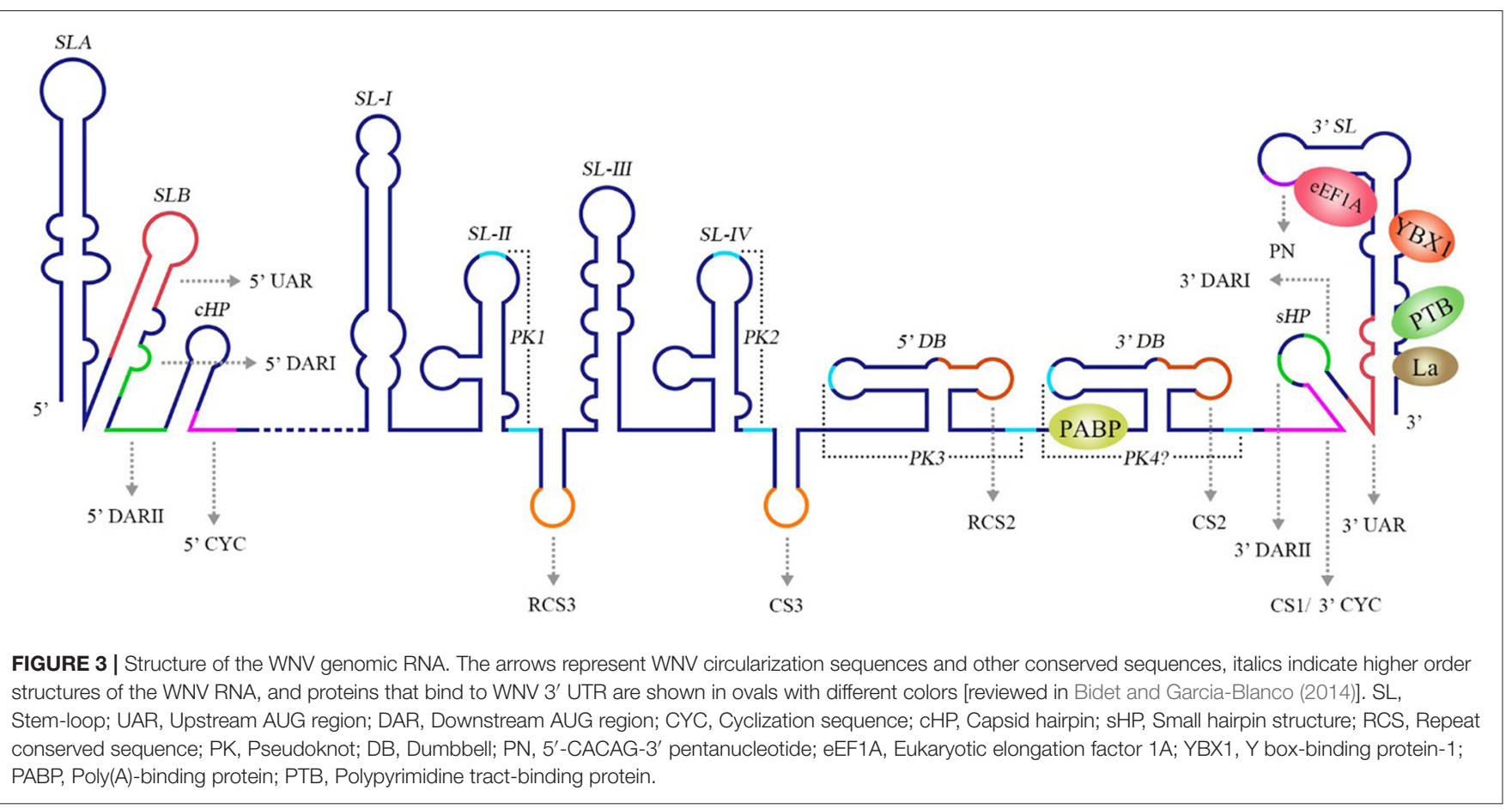

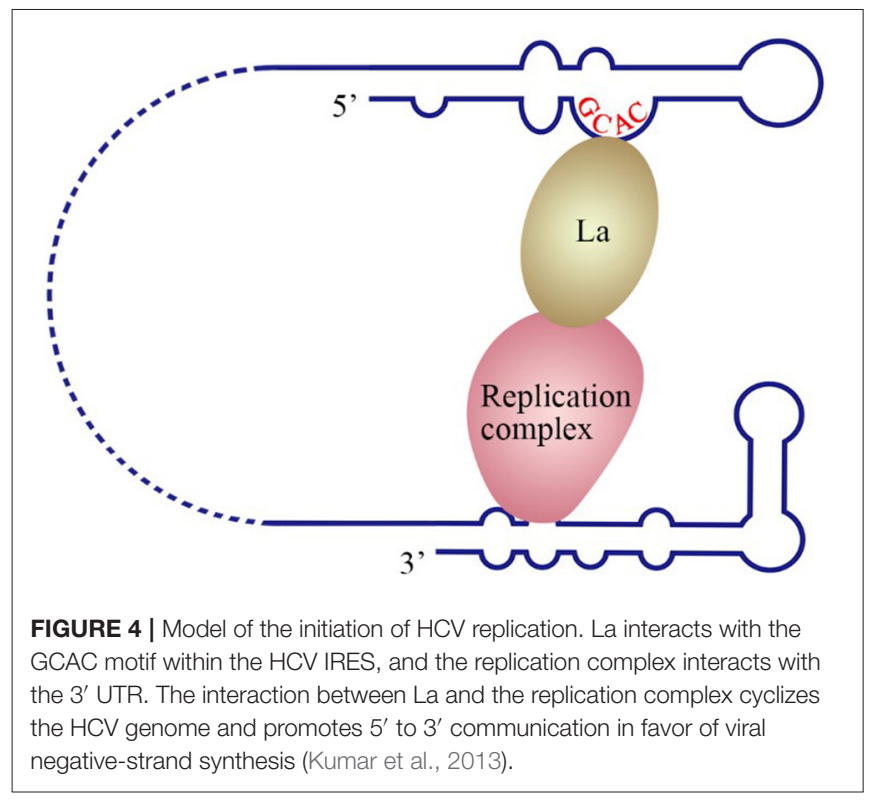

et al., 2007), which is associated with the competition between HuR and PTB for the 3' UTR (Shwetha et al., 2015). However, the binding of PTB to the MHV $3^{\prime}$ SL does not affect viral translation (Choi et al., 2002). Similar to the PTB, the cellular factors PABP and PCBP also bind to the $3^{\prime}$ UTR of HCV, NV, and DENV, and regulate viral replication and translation (Herold and Andino, 2001; Tingting et al., 2006; Polacek et al., 2009b; Bailey et al., 2010; Ogram et al., 2010), but the mechanism remains to be studied.
Eukaryotic elongation factor $1 \mathrm{~A}$ (eEF1A) binds to the stem region close to CS1 in the $3^{\prime}$ UTRs of WNV and DENV (Blackwell and Brinton, 1997; De Nova-Ocampo et al., 2002). The binding of eEF1A to the $3^{\prime}$ UTR is required for WNV and BVDV replication, as confirmed by the co-localization of eEF1A with the WNV and BVDV replication complexes (Johnson et al., 2001; Davis et al., 2007). Notably, eEF1A facilitates WNV replication by enhancing the interaction between the $3^{\prime}$ UTR and the replication complex of WNV (Davis et al., 2007). Nevertheless, eEF1A binds to HCV NS4A and decreases the viral translation efficiency (Kou et al., 2006), suggesting that eEF1A has multiple functions during the replication of members of the Flaviviridae family. On the other hand, eEF1A binds to and activate cellular sphingosine kinase 1 (SphK1) (Leclercq et al., 2008), which is involved in inflammatory response and immunomodulation [reviewed in Carr et al. (2013b), Bezgovsek et al. (2018)] and its activity is affected by the DENV-2 3' UTR (Carr et al., 2013a). Thus, the DENV-2 3' UTR is postulated to compete with SphK1 for binding to eEF1A and inhibits SphK1 activation, which may be relevant to DENV pathogenicity.

The cellular factors T-cell intracellular antigen-1 (TIA-1) and T-cell intracellular antigen-related protein (TIAR) are important components of stress particles (SGs), which respond to cellular stress responses such as viral infections. TIAR/TIA-1 can be utilized by viruses and localized in viral replication complexes. TIA-1 and TIAR bind to two short sequences consisting of AU in the stem-loop of the negative strand of WNV $3^{\prime}$ UTR and are involved in WNV replication (Li et al., 2002; MazanMamczarz et al., 2006; Emara and Brinton, 2007). Furthermore, TIA-1/TIAR together with the WNV $3^{\prime}$ UTR facilitate the subsequent asymmetric amplification of the viral RNA genome 

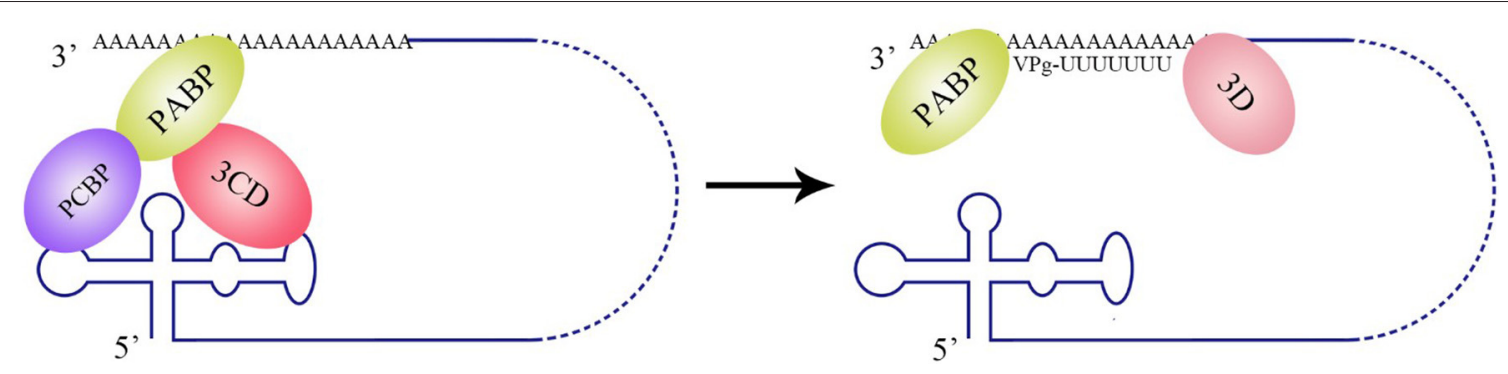

FIGURE 5 | Circularization of the PV genome and initiation of negative-strand RNA synthesis. PV polypeptide and cellular factor poly(C)-binding protein (PCBP) bind to the $5^{\prime}$ UTR cloverleaf, and cellular factor poly(A)-binding protein (PABP) binds to the $3^{\prime}$ UTR. 3CD, PCBP, and PABP interact with each other and lead to the cyclization of the genomic RNA, which brings the viral RdRP (3D protein) in close proximity to the $3^{\prime}$ poly $(A)$ tail and facilitates the initiation of negative-strand RNA synthesis (Herold and Andino, 2001).

from the minus-strand template, but have little effect on the viral translation efficiency (Emara et al., 2008). Meanwhile, TIA1/TIAR bind to the TBEV RNA and inhibit viral replication and early viral translation, and this regulation likely determines the amount of RNA available for viral replication and/or assembly (Albornoz et al., 2014). Because both WNV and TBEV are arboviruses, the discrepancy in these results may be attributed to the regulation of viral replication cycle by TIAR/TIA-1. TIAR/TIA- 1 is localized in the viral replication complex and may regulates the conversion of virus from low-level symmetric plusand minus-strand RNA synthesis to asymmetric amplification of plus-strand viral RNA synthesis, thus the role of TIAR/TIA1 in these two stages may be different (Cleaves et al., 1981; Chambers et al., 1990; Emara et al., 2008). Further experiments are needed to explore the effect of TIAR/TIA-1 on viral replication and translation. In addition, similar findings have also been reported for picornaviruses. For instance, the $3^{\prime}$ UTR of human enterovirus D68 (EV-D68) also interacts with TIA1 (Cheng et al., 2020).

In addition to cellular factors, virus-encoded proteins also interact with viral $3^{\prime}$ stem-loops. Classical swine fever virus (CSFV) encodes the protease NS5A and polymerase NS5B that both bind to the $3^{\prime}$ UTR, which contains two stem-loops, SL-1 and SL-2, and NS5A exhibits higher affinity for binding to the $3^{\prime}$ UTR than the NS5B protein. NS5A binds to SL- 1 and SL-2, and the binding of NS5A to SL-1 is more effective than the binding to SL-2; however, NS5B only binds to SL-1 (Sheng et al., 2012). NS5A facilitates viral RNA synthesis at a low concentration, but RNA synthesis is inhibited by a higher concentration of NS5A (Sheng et al., 2010, 2012; Chen et al., 2012). Therefore, it can be hypothesized that a low concentration of NS5A binds to SL-1 along with NS5B and promotes viral RNA replication. However, in the presence of a high concentration of NS5A, the NS5A protein binds SL-2 and SL-1. The binding of NS5A to SL-2 might inhibit viral synthesis by NS5B using the same $3^{\prime}$ UTR as a template. In feline calicivirus (FCV), the nucleolin protein and $3^{\prime}$ UTR bind to and co-localize with viral protease-polymerase NS6 and NS7 proteins in the cytoplasm, and participate in FCV replication (Cancio-Lonches et al., 2011). In addition, the RdRP proteins from encephalomyocarditis virus (EMCV) and duck hepatitis A virus type 1 (DHAV-1) directly bind to the $3^{\prime}$ UTR (Cui et al., 1993; Yu et al., 2017). These results are consistent with the common mechanism used by RdRP from ssRNA(+) viruses to bind to the genomic $3^{\prime}$ UTR and initiate the synthesis of the negative-strand RNA genome (Kok and McMinn, 2009; Lescar and Canard, 2009; Modrow et al., 2013; Paul and Bartenschlager, 2013).

\section{Pseudoknot Structures}

Pseudoknots (PKs) are common RNA tertiary structures formed by the complementary pairing of single loops of different stemloops and are divided into five types, including the hairpin loop and kissing loop (Brierley et al., 2007) (Figure 6). For ssRNA(+) viruses, researches associated with PKs are more common for plant viruses, and PKs used to be called tRNA-1ike structures (TLS) in the early stage since their structural features are similar to tRNAs (Osman and Buck, 2003; Matsuda and Dreher, 2004; Zeenko and Gallie, 2005). Known PKs are widely located in the $5^{\prime}$ UTRs of viral genomes and enhance viral translation (Moes and Wirth, 2007; Easton et al., 2009; Lavender et al., 2010). Nevertheless, PKs in the $3^{\prime}$ UTRs are also indispensable for viral replication and translation.

The DENV 3' UTR contains two dumbbell structures (DB), which complements with two terminal loops (TLs) sequences of 5 nucleotides, respectively and forms PKs of the hairpin loop type (Olsthoorn and Bol, 2001; Romero et al., 2006) (Figure 3). The base pairing formed by TL2 and PK1, as well as several bases close to TL2, is important for replication and translation (Manzano et al., 2011). The PK sequence is conserved among mosquitoborne flaviviruses. Mutation of PK1 restrains the interaction between the DENV $5^{\prime}$ UTR and $3^{\prime}$ UTR, and mutation of PK2 blocks the complementary interaction of TL2/PK1 (SztubaSolinska et al., 2013), suggesting that DENV PK1 and PK2 are functionally interrelated. In addition, the last 285 nucleotides of the $3^{\prime}$ UTR of DENV-2 serve as a "packaging signal," recruiting NS2A proteins to interact with its PK3, PK4, and 3' SL to allow the nascent RNA to be recruited from the replication complex to the virion assembly site (Xie et al., 2019).

The HCV NS5B coding region retains several stem-loops containing a 5BSL3.2, which was necessary for HCV replication (Friebe et al., 2005; Diviney et al., 2008; You and Rice, 2008). 5BSL3.2 complements with SL2 in the $3^{\prime}$ UTR and forms a kissing-loop PK, and correct nucleotides pairing in the complementarity region are necessary for efficient HCV 


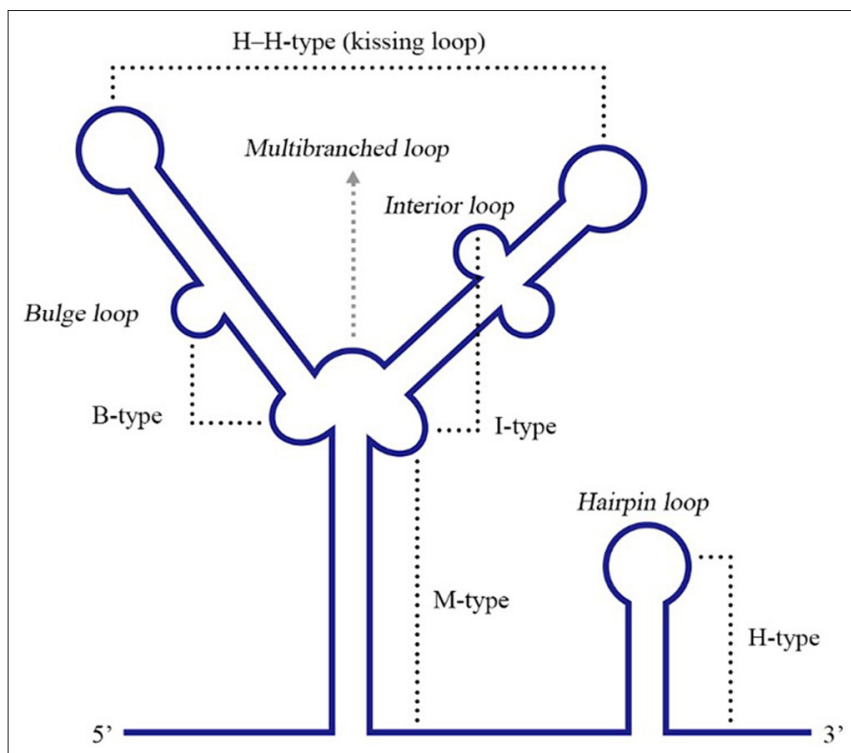

FIGURE 6 | Different types of RNA PK structures. Base pairing between a hairpin loop and a single-stranded region forms a $\mathrm{H}$-type $\mathrm{PK}$, while base paring between a multibranched loop and a single-stranded region forms an M-type PK. A bulge or interior loop together with a multibranched loop can form a B-type or I-type PK. Additionally, two hairpin loops form an $\mathrm{H}-\mathrm{H}$-type PK. Adapted from Brierley et al. (2007). This figure has been approved by the original author and obtained the licenses through Rights Licensing Expert (www.copyright.com), the license number was 4045340264208. replication (Friebe et al., 2005; Diviney et al., 2008). In addition, a 55 nt-long sequence in the $\mathrm{X}$ region of the $\mathrm{HCV}$ $3^{\prime}$ UTR is completely conserved among all HCV strains, and dimerizes and forms a kissing loop PK in the presence of the virus-encoded core protein (Ivanyi-Nagy et al., 2006). On the other hand, the $\mathrm{HCV}$ core protein was reported to bind to the $\mathrm{X}$ region ( $\mathrm{Yu}$ et al., 2009), and mutation analyses showed that dimerization or the PK were relevant to viral replication (Shetty et al., 2010). A logical hypothesis is that the $\mathrm{HCV}$ core protein binds to a $\mathrm{PK}$ formed by sequences in the $3^{\prime}$ UTR $X$ region and participates in viral replication.

The stem-loop structure of $3^{\prime}$ UTR of some viruses [such as porcine reproductive and respiratory syndrome virus (PRRSV) and equine arteritis virus (EAV)] and viral nucleocapsid protein coding region forms a PK. A highly conserved 34 nt-long sequence of the PRRSV nucleocapsid protein coding region was predicted to fold into a stem-loop and was required for viral RNA replication. Furthermore, 7 nucleotides in the loop region of this stem-loop bind complementarily with a loop in a $3^{\prime}$ UTR stemloop and form a hairpin loop PK that is necessary for the efficient synthesis of the viral RNA (Verheije et al., 2002). For EAV, the stem-loop structure SL5 of 3' UTR, together with the stem-loop SL4 of the nucleocapsid protein coding region, form a hairpin loop $\mathrm{PK}$, which is comparatively conserved among arteritis viruses and is relevant to the regulation of viral RNA synthesis (Beerens and Snijder, 2007).

\section{Other High-Order Structures}

The DENV 3' UTR can fold into two dumbbell structures termed DB1 and DB2 (Figure 3). DENV replication requires the binding of the cellular protein DEAD-box RNA helicase DDX6 to DB1 and DB2 (Ward et al., 2011). Mutations of CS2 and RCS2, which are located in DB1 and DB2, reduce the efficiency of DENV2 translation (Wei et al., 2009). The two dumbbell structures and two terminal loops (TLs) form two PKs, which are important for DENV replication and translation (Olsthoorn and Bol, 2001; Romero et al., 2006; Manzano et al., 2011; Sztuba-Solinska et al., 2013). Moreover, the circularization of the flavivirus genome folds the 5' UTR and 3' UTR into a panhandle structure (Villordo and Gamarnik, 2009; Lloyd, 2015), which ensures the efficient initiation of the synthesis of the negative-strand RNA genome. Ochsenreiter et al. (2019), inferred the existence of novel conserved elements in insect-specific flaviviruses (ISFVs) 3' UTR through covariance models, which may be related to functional importance.

\section{OTHER FUNCTIONS OF THE $3^{\prime}$ UTR}

As shown in Tables 1, 2, most research associated with the ssRNA $(+)$ virus $3^{\prime}$ UTR has focused on viral replication and translation, but the role of the $3^{\prime}$ UTR is by no means limited to these processes. Although numerous studies are not directly based on a certain primary or high-order structure, they have highlighted the important roles of $3^{\prime}$ UTRs in life events of the virus and host.

\section{Interacting With miRNAs}

miRNAs, which are transcribed by the host or virus, are a type of small single-stranded RNAs with the length of $\sim 19-25 \mathrm{nt}$. They post-transcriptionally regulate the expression level of the target mRNA by forming the RNA-induced silencing complex (RISC). The ssRNA(+) virus genome is directly used as an mRNA to translate viral proteins, which creates conditions for the miRNA to regulate its expression. miRNAs bind to the $5^{\prime}$ UTR, $3^{\prime}$ UTR or coding regions of the viral genome, which is very important for the viral life cycle.

The $3^{\prime}$ UTR of the ssRNA(+) viruses contain miRNA binding sites that interact with the host miRNAs or viral miRNAs to modulate a series of activities in its viral cycle. miR-17 expressed in MDBK cells interacts with the $3^{\prime}$ UTR of bovine viral diarrhea virus (BVDV), enhancing its replication, translation, and RNA stability (Scheel et al., 2016). miR-133a expressed in Vero cells targets the $3^{\prime}$ UTR of the DENV and PTB mRNA in cells. In the early stage of DENV infection, the $3^{\prime}$ UTR of the virus inhibits miR-133a and increases the expression of the PTB protein, which is required for viral replication and translation (Castillo et al., 2016). The 3' UTR of chikungunya virus (CHIKV) binds to miR-2944b-5p and miR-2b of Ae. aegypti cells, but miR2944b-5p significantly increases viral infection (Dubey et al., 2019). On the other hand, miRNAs have also been reported to suppress viral replication. The 3' UTR of Eastern equine encephalitis virus (EEEV) contains four miRNA binding sites, namely, three canonical and one non-canonical miR-142-3p sites (Trobaugh et al., 2014). miR-142-3p interacts with the $3^{\prime}$ UTR of 
EEEV, preventing its replication and translation in myeloid cells (Trobaugh et al., 2014). Mutations at these sites enhance EEEV replication, resulting in higher levels of IFN $\alpha / \beta$ production, which attenuate viral virulence and prolong the survival of mice (Trobaugh et al., 2019). Interestingly, mosquitoes do not express miR-142-3p, but mutations in the miR-142-3p binding site on the EEEV $3^{\prime}$ UTR inhibit virus replication in mosquito cells (Trobaugh et al., 2019). It is speculated other miRNAs in mosquito cells may interact with these binding sites.

\section{Involvement in sfRNA Formation}

In eukaryotic cells, mRNA avoids degradation by endo- and exoribonucleases in the cell through a $5^{\prime}$ cap structure and a $3^{\prime}$ poly(A) tail. However, flaviviruses contain a cap structure at the $5^{\prime}$-end genomic RNA, but do not have poly(A)-tail and terminate with a stem loop structure $\left(3^{\prime} \mathrm{SL}\right)$. This $3^{\prime} \mathrm{SL}$ can protect viral RNA from $3^{\prime}$ to $5^{\prime}$ exoribonucleases, so $5^{\prime}$ to $3^{\prime}$ degradation by exoribonuclease Xrn-1 are likely to be the predominant pathways (Ford and Wilusz, 1999; Narayanan and Makino, 2013).

The genomic RNA of both mosquito- and tick-borne flaviviruses can be digested incompletely by the host's Xrn1 that halts at the Xrn1-resistant RNA (xrRNA) structures within the $3^{\prime}$ UTR and produces a short subgenomic flavivirus RNA (sfRNA). xrRNA appear to be ubiquitously present in many flaviviruses and xrRNA halts diverse exoribonucleases, in addition to Xrn1 (MacFadden et al., 2018; Ochsenreiter et al., 2019). sfRNA has multiple functions, participating in viral cytopathicity and pathogenicity, immune and anti-viral responses of the host and dysregulating endogenous mRNA turnover (Pijlman et al., 2008; Jones et al., 2012; Schnettler et al., 2012, 2014; Chang et al., 2013; Manokaran et al., 2015; Pompon et al., 2017). In addition, sfRNAs have recently been shown to interact with various RNA-binding proteins in cells to regulate RNA decay and splicing (Michalski et al., 2019).

The RNA structure at the $3^{\prime}$ UTR is necessary for sfRNA formation (Figure 7). SL-II, SL-IV, DB1, and DB2 in WNV $3^{\prime}$ UTR are required for production of sfRNAs 1-4, respectively (Pijlman et al., 2008; Funk et al., 2010). Recent research shows that RCS3, CS3, RCS2, and CS2 in WNV 3' UTR are also involved in the production of their corresponding upstream sfRNAs. Among these sequences, RCS3 increases the binding affinity of xrRNA and Xrn1 and stabilizes the three-dimensional structure of the xrRNA (Zhang et al., 2020). Furthermore, the PK is critical for xrRNA function. PK1, PK2, and PK3 blocks degradation of WNV genomic RNA (gRNA), resulting in accumulation of sfRNA (Funk et al., 2010). A similar situation also exists in other flaviviruses. The YFV $3^{\prime}$ UTR was predicted to contain three potential PKs, and researchers have confirmed that pseudoknot 3 (PSK3) serves as the molecular signal to stall Xrn1 and ultimately produce the YFV sfRNA (Silva et al., 2010). Interestingly, Xrn1 knockdown results in a change in the overall ZIKV sfRNA pattern (Akiyama et al., 2016). However, ZIKV sfRNAs inhibit the activity of Xrn 1 and disrupt the production of the host mRNA (Michalski et al., 2019). The inhibitory effect of sfRNA on Xrn1 has also been reported in DENV and KUNV (Moon et al., 2012). The production of sfRNA may be a dynamically balanced process, that is to say, once the amount of sfRNA accumulates to a certain level, the activity of Xrn1 will be inhibited and the sfRNAs will exert their regulatory effects.

\section{Role in Virulence}

The effect of the $3^{\prime}$ UTR on virus virulence has been reported. Changes in a certain sequence or structure of the $3^{\prime}$ UTR exert a significant effect on viral virulence. The $3^{\prime}$ UTR polypyrimidine sequence affects the virulence of MNV (Bailey et al., 2010). In addition, the $10577 \mathrm{~T}$ mutation in the WNV $3^{\prime}$ UTR significantly attenuates its virulence (Zhang et al., 2020). The $3^{\prime}$ UTR variable region is the main factor that determines the differential virulence of two strains of TBEV (Sakai et al., 2014), and partial deletion of the secondary structure elements in the $3^{\prime}$ UTR obviously enhanced the virulence, indicating that TBEV virulence is modulated by the secondary structures in the $3^{\prime}$ UTR variable region (Sakai et al., 2015). Similarly, the miR-142-3p binding site on the $3^{\prime}$ UTR of EEEV plays an important role in its virulence (Trobaugh et al., 2019). The impact of the $3^{\prime}$ UTR on virulence has great prospects for the development of live attenuated vaccines.

\section{Role in Virus Evolution}

A small hairpin structure (sHP) (Figure 3) is required for DENV replication in mosquito cells, but not in mammalian cells (Villordo and Gamarnik, 2013); furthermore, DENV RNA structures are relevant to host specialization (Villordo et al., 2015). Similar results have also been reported for Chikungunya virus (CHIKV) and Sindbis virus (SINV), as the $3^{\prime}$ UTRs of these two viruses function as an evolutionary force to adapt to mosquito cells, but not mammalian cells (Chen et al., 2013; Garcia-Moreno et al., 2016). In addition, the sfRNA produced by the flavivirus $3^{\prime}$ UTR participates in regulating host adaptation. DENV generates different patterns of sfRNAs in mosquito or human cells and these patterns rapidly change upon host switching (Filomatori et al., 2017). Similarly, ZIKV infects different cell types to produce different sfRNA patterns (Akiyama et al., 2016). Based on these findings, the sequence and structure of the $3^{\prime}$ UTR must play significant roles in the host adaption and evolution of the ssRNA(+) virus, but the existing data are still very poor and more extensive research is needed.

\section{Role in the Immune and Anti-viral Responses of the Host}

The FMDV 3' UTR functions as a pathogen-associated molecular pattern (PAMP) and participates in reorganizing and activating the synthesis of the alpha/beta interferon (INF- $\alpha / \beta)$ mRNA, and the $3^{\prime}$ UTR secondary structure was an important factor contributing to the synthesis of these cytokine (Rodríguez-Pulido et al., 2011). Similarly, the poly-U/UC tract of HCV functions as the PAMP substrate of retinoic acid inducible gene I (RIG-I), since RIG-I was shown to recognize and bind to this region (Saito et al., 2008; Schnell et al., 2012). The infection of DENV2 strain with high epidemiological fitness or the chimeric virus with high epidemiological strain $3^{\prime}$ UTR inhibited gene expression for the Toll-pathway component Rel1a and CecG in mosquito salivary glands (Pompon et al., 2017). Moreover, the deletion of the four miR-142-3p binding sites in the $3^{\prime}$ UTR of EEEV result in 


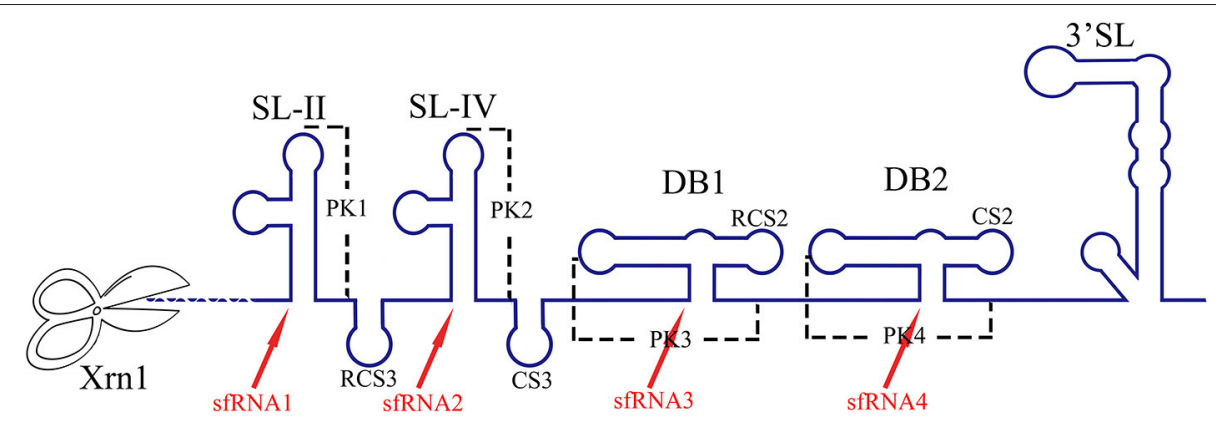

FIGURE 7 | The biogenesis of sfRNA in WNV-infected cells. The primary sequences (RCS3, CS3, RCS2, CS2) and higher order structures (SL-II, SL-IV, DB1, DB2, PK1, PK2, PK3) of the WNV 3' UTR are required for production of sfRNAs (Pijlman et al., 2008; Funk et al., 2010; Zhang et al., 2020).

higher levels of cytokine and chemokine transcription than wild type EEEV (Trobaugh et al., 2019). Thus, specific sequences and structural elements of the ssRNA(+) virus $3^{\prime}$ UTR can mediate the innate immune and anti-viral responses of the host.

In addition, sfRNA produced by $3^{\prime}$ UTR has also been reported in antiviral responses. The predominant antiviral innate immune strategy relies on RNA interference (RNAi) pathway in invertebrates (Olson and Blair, 2015). To evade RNAi response, WNV sfRNA efficiently suppressed siRNA- and miRNA-induced RNAi pathways in insect cells (Schnettler et al., 2012). However, when the host becomes a vertebrate, sfRNA can inhibit the production of type 1 interferon. Replication of sfRNA-deficient $\mathrm{WNV}$ was rescued in MEFs lacking interferon regulatory factor 3 (IRF-3) and IRF-7 and in mice lacking the type I alpha/beta interferon receptor (IFNAR) (Schuessler et al., 2012). Similarly, IFN antagonist activity of ZIKV, DENV, and JEV sfRNA was also confirmed (Chang et al., 2013; Manokaran et al., 2015; Donald et al., 2016). These results indicate that the study of sfRNA is important for further understanding the pathogenesis and virus-host interaction.

\section{PERSPECTIVES}

A certain function is determined by a specific structure, and thus a functional study base on structure is more generally convincing. Here, we describe the primary and higher order structures of the ssRNA(+) virus $3^{\prime}$ UTR, and the function of $3^{\prime}$ UTR for viral replication, translation, virulence, evolution, and the immune response. Therefore, studies of the $3^{\prime}$ UTR are necessary to identify the common mechanisms regulating the life events of all $\operatorname{ssRNA}(+)$ viruses.

Life events of the virus and host can be modulated by the interaction between viral $3^{\prime}$ UTR and viral/cellular proteins. On the other hand, the proteins interacting with the $3^{\prime}$ UTR may interact with each other, forming protein-protein interactions, which complement the RNA-protein interactions. These proteinprotein and RNA-protein interactions form a large network participating in the regulation of viruses and hosts. However, little is known about these protein-protein interactions, and thus more studies are needed, which will be promising to investigate the complete regulatory network of the ssRNA $(+)$ virus $3^{\prime}$ UTR.

The ssRNA $(+)$ viruses use its genome as mRNA to directly translate viral proteins, which can attract miRNAs transcribed by the host or virus to interact with their genome and regulate the viral life cycle. Given the importance of $3^{\prime}$ UTR to viral replication and translation, the design of an artificial miRNA (amiRNA) targeting the sequence of the $3^{\prime}$ UTR of the ssRNA(+) virus or the insertion of a targeting sequence for the miRNA that inhibits viral replication at the $3^{\prime}$ UTR will provide a new strategy for the treatment of infections with ssRNA(+) viruses. In addition, deleting or mutating certain base sequences in the $3^{\prime}$ UTR disrupts the circularization of the genome, which also provides ideas for the development of new vaccines.

\section{AUTHOR CONTRIBUTIONS}

YuaL, YZ, and MW conceived, designed, and wrote the manuscript. AC, QY, YWu, RJ, ML, DZ, SC, SZ, XZ, JH, SM, XO, and QG revised with the manuscript. YWa, ZX, ZC, LZhu, QL, YunL, YY, LZha, BT, LP, and XC helped with the manuscript. All authors read and approved the final manuscript for publication.

\section{FUNDING}

This work was supported by the National Key Research and Development Program of China (2017YFD0500800), the China Agricultural Research System (CARS-42-17), the Sichuan Veterinary Medicine and Drug Innovation Group of China Agricultural Research System (SCCXTD-2020-18).

\section{ACKNOWLEDGMENTS}

We thank Prof. Andrea V. Gamarnik for kindly providing access to the images. 


\section{REFERENCES}

Akiyama, B. M., Laurence, H. M., Massey, A. R., Costantino, D. A., Xie, X., Yang, Y., et al. (2016). Zika virus produces noncoding RNAs using a multipseudoknot structure that confounds a cellular exonuclease. Science 354, 1148-1152. doi: 10.1126/science.aah3963

Albornoz, A., Carletti, T., Corazza, G., and Marcello, A. (2014). The stress granule component TIA-1 binds tick-borne encephalitis virus RNA and is recruited to perinuclear sites of viral replication to inhibit viral translation. J. Virol. 88, 6611-6622. doi: 10.1128/JVI.03736-13

Alvarez, D. E., Lodeiro, M. F., Ludueña, S. J., Pietrasanta, L. I., and Gamarnik, A. V. (2005). Long-range RNA-RNA interactions circularize the dengue virus genome. J. Virol. 79, 6631-6643. doi: 10.1128/JVI.79.11.6631-6643.2005

Bai, Y., Zhou, K., and Doudna, J. A. (2013). Hepatitis C virus $3^{\prime}$ UTR regulates viral translation through direct interactions with the host translation machinery. Nucleic Acids Res. 41, 7861-7874. doi: 10.1093/nar/gkt543

Bailey, D., Karakasiliotis, I., Vashist, S., Chung, L. M. W., Reese, J., McFadden, N., et al. (2010). Functional analysis of RNA structures present at the $3^{\prime}$ extremity of the murine norovirus genome: the variable polypyrimidine tract plays a role in viral virulence. J. Virol. 84, 2859-2870. doi: 10.1128/JVI.02053-09

Basu, M., and Brinton, M. A. (2011). West Nile virus (WNV) genome RNAs with up to three adjacent mutations that disrupt long distance $5^{\prime}-3^{\prime}$ cyclization sequence basepairs are viable. Virology 412, 220-232. doi: 10.1016/j.virol.2011.01.008

Beerens, N., and Snijder, E. J. (2007). An RNA pseudoknot in the $3^{\prime}$ end of the arterivirus genome has a critical role in regulating viral RNA synthesis. J. Virol. 81, 9426-9436. doi: 10.1128/JVI.00747-07

Bezgovsek, J., Gulbins, E., Friedrich, S. K., Lang, K. S., and Duhan, V. (2018). Sphingolipids in early viral replication and innate immune activation. Biol. Chem. 399, 1115-1123. doi: 10.1515/hsz-2018-0181

Bidet, K., Dadlani, D., and Garcia-Blanco, M. A. (2014). G3bp1, g3bp2 and caprin1 are required for translation of interferon stimulated mRNAs and are targeted by a dengue virus non-coding RNA. PLoS Pathog. 10:e1004242. doi: 10.1371/journal.ppat.1004242

Bidet, K., and Garcia-Blanco, M. A. (2014). Flaviviral RNAs: weapons and targets in the war between virus and host. Biochem. J. 462, 215-230. doi: 10.1042/BJ20140456

Blackwell, J. L., and Brinton, M. A. (1997). Translation elongation factor-1 alpha interacts with the $3^{\prime}$ stem-loop region of West Nile virus genomic RNA. J. Virol. 71, 6433-6444. doi: 10.1128/JVI.71.9.6433-6444.1997

Brierley, I., Pennell, S., and Gilbert, R. J. (2007). Viral RNA pseudoknots: versatile motifs in gene expression and replication. Nat. Rev. Microbiol. 5, 598-610. doi: $10.1038 /$ nrmicro 1704

Brocard, M., Paulous, S., Komarova, A. V., Deveaux, V., and Kean, K. M. (2007). Evidence that PTB does not stimulate HCV IRES-driven translation. Virus Genes 35, 5-15. doi: 10.1007/s11262-006-0038-z

Cancio-Lonches, C., Yocupicio-Monroy, M., Sandoval-Jaime, C., GalvanMendoza, I., Urena, L., Vashist, S., et al. (2011). Nucleolin interacts with the feline calicivirus $3^{\prime}$ untranslated region and the protease-polymerase NS6 and NS7 proteins, playing a role in virus replication. J. Virol. 85, 8056-8068. doi: 10.1128/JVI.01878-10

Cao, J., Ou, X., Zhu, D., Ma, G., Cheng, A., Wang, M., et al. (2016). The 2 A2 protein of duck hepatitis A virus type 1 induces apoptosis in primary cell culture. Virus Genes 52, 780-788. doi: 10.1007/s11262-016-1364-4

Cao, Q., Cheng, A., and Wang, M. (2012). Characteristics and function of 3D gene and its encoding protein in picornavirus. Rev. Med. Microbiol. 23, 18-22. doi: 10.1097/MRM.0b013e328352afee

Cao, Q. D., Cheng, A. C., and Wang, M. S. (2013). Bioinformatic analysis of the 3D polyprotein from duck hepatitis A virus strain $\mathrm{H}$ isolated in China. Adv. Mater. Res. 647, 396-402. doi: 10.4028/www.scientific.net/AMR.647.396

Carr, J. M., Kua, T., Clarke, J. N., Calvert, J. K., Zebol, J. R., Beard, M. R., et al. (2013a). Reduced sphingosine kinase 1 activity in dengue virus type- 2 infected cells can be mediated by the $3^{\prime}$ untranslated region of dengue virus type- 2 RNA. J. Gen. Virol. 94(Pt 11), 2437-2448. doi: 10.1099/vir.0.055616-0

Carr, J. M., Mahalingam, S., Bonder, C. S., and Pitson, S. M. (2013b). Sphingosine kinase 1 in viral infections. Rev. Med. Virol. 23, 73-84. doi: 10.1002/rmv.1718

Castillo, J. A., Castrillon, J. C., Diosa-Toro, M., Betancur, J. G., St Laurent, G., III, Smit, J. M., et al. (2016). Complex interaction between dengue virus replication and expression of miRNA-133a. BMC Infect. Dis. 16:29. doi: 10.1186/s12879-016-1364-y

Chambers, T. J., Hahn, C. S., Galler, R., and Rice, C. M. (1990). Flavivirus genome organization, expression, and replication. Annu. Rev. Microbiol. 44, 649-688. doi: 10.1146/annurev.mi.44.100190.003245

Chang, K.-S., and Luo, G. (2006). The polypyrimidine tract-binding protein (PTB) is required for efficient replication of hepatitis C virus (HCV) RNA. Virus Res. 115, 1-8. doi: 10.1016/j.virusres.2005.06.012

Chang, R. Y., Hsu, T. W., Chen, Y. L., Liu, S. F., Tsai, Y. J., Lin, Y. T., et al. (2013). Japanese encephalitis virus non-coding RNA inhibits activation of interferon by blocking nuclear translocation of interferon regulatory factor 3. Vet. Microbiol. 166, 11-21. doi: 10.1016/j.vetmic.2013.04.026

Chen, R., Wang, E., Tsetsarkin, K. A., and Weaver, S. C. (2013). Chikungunya virus $3^{\prime}$ untranslated region: adaptation to mosquitoes and a population bottleneck as major evolutionary forces. PLoS Pathog. 9:e1003591. doi: 10.1371/journal.ppat.1003591

Chen, Y., Xiao, J., Xiao, J., Sheng, C., Wang, J., Jia, L., et al. (2012). Classical swine fever virus NS5A regulates viral RNA replication through binding to NS5B and 3' UTR. Virology 432, 376-388. doi: 10.1016/j.virol.2012.04.014

Cheng, J., Gao, S., Zhu, C., Liu, S., Li, J., Kang, J., et al. (2020). Typical stress granule proteins interact with the $3^{\prime}$ untranslated region of enterovirus D68 to inhibit viral replication. J. Virol. 94:e02041-19. doi: 10.1128/JVI.02041-19

Chien, H.-L., Liao, C.-L., and Lin, Y.-L. (2011). FUSE binding protein 1 interacts with untranslated regions of Japanese encephalitis virus RNA and negatively regulates viral replication. J. Virol. 85, 4698-4706. doi: 10.1128/JVI.01950-10

Choi, K. S., Huang, P., and Lai, M. M. (2002). Polypyrimidine-tract-binding protein affects transcription but not translation of mouse hepatitis virus RNA. Virology 303, 58-68. doi: 10.1006/viro.2002.1675

Cleaves, G. R., Ryan, T. E., and Schlesinger, R. W. (1981). Identification and characterization of type 2 dengue virus replicative intermediate and replicative form RNAs. Virology 111, 73-83. doi: 10.1016/0042-6822(81)90654-1

Collisson, E. W., Zhou, M., Gershon, P., and Jayaram, J. (2001). "Infectious bronchitis virus nucleocapsid protein interactions with the $3^{\prime}$ untranslated region of genomic RNA depend on uridylate bases," in The Nidoviruses: Coronaviruses and Arteriviruses, eds E. Lavi, S. R. Weiss, and S. T. Hingley (New York, NY: Kluwer Academic; Plenum Publishers), 669-675. doi: 10.1007/978-1-4615-1325-4_99

Cui, T., Sankar, S., and Porter, A. G. (1993). Binding of encephalomyocarditis virus RNA polymerase to the $3^{\prime}$-noncoding region of the viral RNA is specific and requires the $3^{\prime}$-poly(A) tail. J. Biol. Chem. 268, 26093-26098.

Davis, W. G., Blackwell, J. L., Shi, P.-Y., and Brinton, M. A. (2007). Interaction between the cellular protein eEF1A and the $3^{\prime}$-terminal stem-loop of West Nile virus genomic RNA facilitates viral minus-strand RNA synthesis. J. Virol. 81, 10172-10187. doi: 10.1128/JVI.00531-07

De Nova-Ocampo, M., Villegas-Sepúlveda, N., and del Angel, R. M. (2002). Translation elongation factor- $1 \alpha, \mathrm{La}$, and PTB interact with the $3^{\prime}$ untranslated region of dengue 4 virus RNA. Virology 295, 337-347. doi: 10.1006/viro.2002.1407

Diviney, S., Tuplin, A., Struthers, M., Armstrong, V., Elliott, R. M., Simmonds, P., et al. (2008). A hepatitis $C$ virus cis-acting replication element forms a longrange RNA-RNA interaction with upstream RNA sequences in NS5B. J. Virol. 82, 9008-9022. doi: 10.1128/JVI.02326-07

Donald, C. L., Brennan, B., Cumberworth, S. L., Rezelj, V. V., Clark, J. J., Cordeiro, M. T., et al. (2016). Full genome sequence and sfRNA interferon antagonist activity of zika virus from Recife, Brazil. PLoS Negl. Trop. Dis. 10:e0005048. doi: 10.1371/journal.pntd.0005048

Dong, H., Ray, D., Ren, S., Zhang, B., Puig-Basagoiti, F., Takagi, Y., et al. (2007). Distinct RNA elements confer specificity to flavivirus RNA cap methylation events. J. Virol. 81, 4412-4421. doi: 10.1128/JVI.02455-06

Dong, H., Zhang, B., and Shi, P.-Y. (2008). Terminal structures of West Nile virus genomic RNA and their interactions with viral NS5 protein. Virology 381, 123-135. doi: 10.1016/j.virol.2008.07.040

Dong, Y., Yang, J., Ye, W., Wang, Y., Miao, Y., Ding, T., et al. (2015). LSm1 binds to the Dengue virus RNA $3^{\prime}$ UTR and is a positive regulator of dengue virus replication. Int. J. Mol. Med. 35, 1683-1689. doi: 10.3892/ijmm.2015. 2169

Dubey, S. K., Shrinet, J., and Sunil, S. (2019). Aedes aegypti microRNA, miR$2944 \mathrm{~b}-5 \mathrm{p}$ interacts with $3^{\prime}$ UTR of chikungunya virus and cellular target 
vps-13 to regulate viral replication. PLoS Negl. Trop. Dis. 13:e0007429. doi: 10.1371/journal.pntd.0007429

Easton, L. E., Locker, N., and Lukavsky, P. J. (2009). Conserved functional domains and a novel tertiary interaction near the pseudoknot drive translational activity of hepatitis $\mathrm{C}$ virus and hepatitis $\mathrm{C}$ virus-like internal ribosome entry sites. Nucleic Acids Res. 37, 5537-5549. doi: 10.1093/nar/gkp588

Elghonemy, S., Davis, W. G., and Brinton, M. A. (2005). The majority of the nucleotides in the top loop of the genomic $3^{\prime}$ terminal stem loop structure are cis-acting in a West Nile virus infectious clone. Virology 331, 238-246. doi: 10.1016/j.virol.2004.11.008

Emara, M. M., and Brinton, M. A. (2007). Interaction of TIA-1/TIAR with West Nile and dengue virus products in infected cells interferes with stress granule formation and processing body assembly. Proc. Natl. Acad. Sci. U.S.A. 104, 9041-9046. doi: 10.1073/pnas.0703348104

Emara, M. M., Liu, H., Davis, W. G., and Brinton, M. A. (2008). Mutation of mapped TIA-1/TIAR binding sites in the $3^{\prime}$ terminal stem-loop of West Nile virus minus-strand RNA in an infectious clone negatively affects genomic RNA amplification. J. Virol. 82, 10657-10670. doi: 10.1128/JVI.00991-08

Espinosa-Hernandez, W., Velez-Uriza, D., Valdes, J., Velez-Del Valle, C., SalasBenito, J., Martinez-Contreras, R., et al. (2014). PTB binds to the $3^{\prime}$ untranslated region of the human astrovirus type 8: a possible role in viral replication. PLoS ONE 9:e113113. doi: 10.1371/journal.pone.0113113

Filomatori, C. V., Carballeda, J. M., Villordo, S. M., Aguirre, S., Pallarés, H. M., Maestre, A. M., et al. (2017). Dengue virus genomic variation associated with mosquito adaptation defines the pattern of viral non-coding RNAs and fitness in human cells. PLoS Pathog. 13:e1006265. doi: 10.1371/journal.ppat.1006265

Filomatori, C. V., Lodeiro, M. F., Alvarez, D. E., Samsa, M. M., Pietrasanta, L., and Gamarnik, A. V. (2006). A 5 ' RNA element promotes dengue virus RNA synthesis on a circular genome. Genes Dev. 20, 2238-2249. doi: $10.1101 /$ gad.1444206

Ford, L. P., and Wilusz, J. (1999). $3^{\prime}$-terminal RNA structures and poly(U) tracts inhibit initiation by a $3^{\prime}->5^{\prime}$ exonuclease in vitro. Nucleic Acids Res. 27, 1159-1167. doi: 10.1093/nar/27.4.1159

Friebe, P., Boudet, J., Simorre, J.-P., and Bartenschlager, R. (2005). Kissing-loop interaction in the $3^{\prime}$ end of the hepatitis $\mathrm{C}$ virus genome essential for RNA replication. J. Virol. 79, 380-392. doi: 10.1128/JVI.79.1.380-392.2005

Friebe, P., Shi, P.-Y., and Harris, E. (2011). The $5^{\prime}$ and $3^{\prime}$ downstream AUG region elements are required for mosquito-borne flavivirus RNA replication. J. Virol. 85, 1900-1905. doi: 10.1128/JVI.02037-10

Funk, A., Truong, K., Nagasaki, T., Torres, S., Floden, N., Balmori Melian, E., et al. (2010). RNA structures required for production of subgenomic flavivirus RNA. J. Virol. 84, 11407-11417. doi: 10.1128/JVI.01159-10

Galán, C., Sola, I., Nogales, A., Thomas, B., Akoulitchev, A., Enjuanes, L., et al. (2009). Host cell proteins interacting with the $3^{\prime}$ end of TGEV coronavirus genome influence virus replication. Virology 391, 304-314. doi: 10.1016/j.virol.2009.06.006

Garcia-Montalvo, B. M., Medina, F., and del Angel, R. M. (2004). La protein binds to NS5 and NS3 and to the $5^{\prime}$ and $3^{\prime}$ ends of dengue 4 virus RNA. Virus Res. 102, 141-150. doi: 10.1016/j.virusres.2004.01.024

Garcia-Moreno, M., Sanz, M. A., and Carrasco, L. (2016). A viral mRNA motif at the $3^{\prime}$-untranslated region that confers translatability in a cell-specific manner. Implications for virus evolution. Sci. Rep. 6:19217. doi: 10.1038/srep19217

Gomila, R. C., Martin, G. W., and Gehrke, L. (2011). NF90 binds the dengue virus RNA $3^{\prime}$ terminus and is a positive regulator of dengue virus replication. PLoS ONE 6:e16687. doi: 10.1371/journal.pone.0016687

Gutiérrez-Escolano, A. L., Vázquez-Ochoa, M., Escobar-Herrera, J., and Hernández-Acosta, J. (2003). La, PTB, and PAB proteins bind to the $3^{\prime}$ untranslated region of Norwalk virus genomic RNA. Biochem. Biophys. Res. Commun. 311, 759-766. doi: 10.1016/j.bbrc.2003. 10.066

Hahn, C. S., Hahn, Y. S., Rice, C. M., Lee, E., Dalgarno, L., Strauss, E. G., et al. (1987). Conserved elements in the $3^{\prime}$ untranslated region of flavivirus RNAs and potential cyclization sequences. J. Mol. Biol. 198, 33-41. doi: 10.1016/0022-2836(87)90455-4

Herold, J., and Andino, R. (2001). Poliovirus RNA replication requires genome circularization through a protein-protein bridge. Mol. Cell 7, 581-591. doi: 10.1016/S1097-2765(01)00205-2
Hoffman, B., Li, Z., and Liu, Q. (2015). Downregulation of viral RNA translation by hepatitis $C$ virus non-structural protein NS5A requires the poly(U/UC) sequence in the 3' UTR. J. Gen. Virol. 96, 2114-2121. doi: 10.1099/vir.0.000141

Holden, K. L., Stein, D. A., Pierson, T. C., Ahmed, A. A., Clyde, K., Iversen, P. L., et al. (2006). Inhibition of dengue virus translation and RNA synthesis by a morpholino oligomer targeted to the top of the terminal $3^{\prime}$ stem-loop structure. Virology 344, 439-452. doi: 10.1016/j.virol.2005.08.034

Huang, P., and Lai, M. M. (1999). Polypyrimidine tract-binding protein binds to the complementary strand of the mouse hepatitis virus $3^{\prime}$ untranslated region, thereby altering RNA conformation. J. Virol. 73, 9110-9116. doi: 10.1128/JVI.73.11.9110-9116.1999

Huang, P., and Lai, M. M. (2001). Heterogeneous nuclear ribonucleoprotein a1 binds to the $3^{\prime}$-untranslated region and mediates potential $5^{\prime}-3^{\prime}$ end cross talks of mouse hepatitis virus RNA. J. Virol. 75, 5009-5017. doi: 10.1128/JVI.75.11.5009-5017.2001

International Committee on Taxonomy of Viruses (2019). ICTV Master Species List 2019.v1. Available online at: https://talk.ictvonline.org/files/master-specieslists/m/msl/9601 (accessed May 12, 2020).

Isken, O., Baroth, M., Grassmann, C. W., Weinlich, S., Ostareck, D. H., OstareckLederer, A., et al. (2007). Nuclear factors are involved in hepatitis C virus RNA replication. RNA 13, 1675-1692. doi: 10.1261/rna.594207

Isken, O., Grassmann, C.W., Yu, H., and, Behrens, S.-E. (2004). Complex signals in the genomic $3^{\prime}$ nontranslated region of bovine viral diarrhea virus coordinate translation and replication of the viral RNA. RNA 10, 1637-1652. doi: $10.1261 /$ rna.7290904

Isken, O., Grassmann, C. W., Sarisky, R. T., Kann, M., Zhang, S., Grosse, F., et al. (2003). Members of the NF90/NFAR protein group are involved in the life cycle of a positive-strand RNA virus. ЕMBO J. 22, 5655-5665. doi: $10.1093 / \mathrm{emboj} / \mathrm{cdg}, 562$

Ito, T., and Lai, M. M. (1999). An internal polypyrimidine-tract-binding protein-binding site in the hepatitis C virus RNA attenuates translation, which is relieved by the $3^{\prime}$-untranslated sequence. Virology 254, 288-296. doi: 10.1006/viro.1998.9541

Ivanyi-Nagy, R., Kanevsky, I., Gabus, C., Lavergne, J.-P., Ficheux, D., Penin, F., et al. (2006). Analysis of hepatitis C virus RNA dimerization and core-RNA interactions. Nucleic Acids Res. 34, 2618-2633. doi: 10.1093/nar/gkl240

Johnson, C. M., Perez, D. R., French, R., Merrick, W. C., and Donis, R. O. (2001). The NS5A protein of bovine viral diarrhoea virus interacts with the a subunit of translation elongation factor-1. J. Gen. Virol. 82, 2935-2943. doi: 10.1099/0022-1317-82-12-2935

Jones, C. I., Zabolotskaya, M. V., and Newbury, S. F. (2012). The $5^{\prime} \rightarrow 3^{\prime}$ exoribonuclease XRN1/Pacman and its functions in cellular processes and development. Wiley Interdiscip. Rev. 3, 455-468. doi: 10.1002/wrna.1109

Katoh, H., Mori, Y., Kambara, H., Abe, T., Fukuhara, T., Morita, E., et al. (2011). Heterogeneous nuclear ribonucleoprotein A2 participates in the replication of Japanese encephalitis virus through an interaction with viral proteins and RNA. J. Virol. 85, 10976-10988. doi: 10.1128/JVI.00846-11

Khromykh, A. A., Kondratieva, N., Sgro, J.-Y., Palmenberg, A., and Westaway, E. G. (2003). Significance in replication of the terminal nucleotides of the flavivirus genome. J. Virol. 77, 10623-10629. doi: 10.1128/JVI.77.19.10623-10629.2003

Khromykh, A. A., and Westaway, E. G. (1997). Subgenomic replicons of the flavivirus Kunjin: construction and applications. J. Virol. 71, 1497-1505. doi: 10.1128/JVI.71.2.1497-1505.1997

Kim, S. M., and Jeong, Y. S. (2006). Polypyrimidine tract-binding protein interacts with the $3^{\prime}$ stem-loop region of Japanese encephalitis virus negative-strand RNA. Virus Res. 115, 131-140. doi: 10.1016/j.virusres.2005.07.013

Kofler, R. M., Hoenninger, V. M., Thurner, C., and Mandl, C. W. (2006). Functional analysis of the tick-borne encephalitis virus cyclization elements indicates major differences between mosquito-borne and tick-borne flaviviruses. J. Virol. 80, 4099-4113. doi: 10.1128/JVI.80.8.4099-4113.2006

Kok, C. C., and McMinn, P. C. (2009). Picornavirus RNA-dependent RNA polymerase. Int. J. Biochem. Cell Biol. 41, 498-502. doi: 10.1016/j.biocel.2008.03.019

Kou, Y.-H., Chou, S.-M., Wang, Y.-M., Chang, Y.-T., Huang, S.-Y., Jung, M.-Y., et al. (2006). Hepatitis $C$ virus NS4A inhibits cap-dependent and the viral IRESmediated translation through interacting with eukaryotic elongation factor $1 \mathrm{~A}$. J. Biomed. Sci. 13, 861-874. doi: 10.1007/s11373-006-9104-8 
Kumar, A., Ray, U., and Das, S. (2013). Human La protein interaction with GCAC near the initiator AUG enhances hepatitis C virus RNA replication by promoting linkage between $5^{\prime}$ and $3^{\prime}$ untranslated regions. J. Virol. 87, 6713-6726. doi: 10.1128/JVI.00525-13

Lai, Y., Zeng, N., Wang, M., Cheng, A., Yang, Q., Wu, Y., et al. (2019). The VP3 protein of duck hepatitis A virus mediates host cell adsorption and apoptosis. Sci. Rep. 9:16783. doi: 10.1038/s41598-019-53285-0

Lavender, C. A., Ding, F., Dokholyan, N. V., and Weeks, K. M. (2010). Robust and generic RNA modeling using inferred constraints: a structure for the hepatitis C virus IRES pseudoknot domain. Biochemistry 49, 4931-4933. doi: 10.1021/bi100142y

Leclercq, T. M., Moretti, P. A., Vadas, M. A., and Pitson, S. M. (2008). Eukaryotic elongation factor $1 \mathrm{~A}$ interacts with sphingosine kinase and directly enhances its catalytic activity. J. Biol. Chem. 283, 9606-9614. doi: 10.1074/jbc.M708782200

Lei, Y., Huang, Y., Zhang, H., Yu, L., Zhang, M., and Dayton, A. (2011). Functional interaction between cellular p100 and the dengue virus $3^{\prime}$ UTR. J. Gen. Virol. 92(Pt 4), 796-806. doi: 10.1099/vir.0.028597-0

Lescar, J., and Canard, B. (2009). RNA-dependent RNA polymerases from flaviviruses and picornaviridae. Curr. Opin. Struct. Biol. 19, 759-767. doi: 10.1016/j.sbi.2009.10.011

Li, C., Ge, L. L., Li, P. P., Wang, Y., Sun, M. X., Huang, L., et al. (2013). The DEADbox RNA helicase DDX5 acts as a positive regulator of Japanese encephalitis virus replication by binding to viral $3^{\prime}$ UTR. Antiviral Res. 100, 487-499. doi: 10.1016/j.antiviral.2013.09.002

Li, W., Li, Y., Kedersha, N., Anderson, P., Emara, M., Swiderek, K., et al. (2002). Cell proteins TIA-1 and TIAR interact with the $3^{\prime}$ stem-loop of the West Nile virus complementary minus-strand RNA and facilitate virus replication. J. Virol. 76, 11989-12000. doi: 10.1128/JVI.76.23.11989-12000.2002

Lin, R.-J., Chien, H.-L., Lin, S.-Y., Chang, B.-L., Yu, H.-P., Tang, W.-C., et al. (2013). MCPIP1 ribonuclease exhibits broad-spectrum antiviral effects through viral RNA binding and degradation. Nucleic Acids Res. 41, 3314-3326. doi: $10.1093 /$ nar/gkt019

Lloyd, R. E. (2015). Nuclear proteins hijacked by mammalian cytoplasmic plus strand RNA viruses. Virology 479, 454-474. doi: 10.1016/j.virol.2015.03.001

Luo, G. (1999). Cellular proteins bind to the poly (U) tract of the $3^{\prime}$ untranslated region of hepatitis C virus RNA genome. Virology 256, 105-118. doi: 10.1006/viro.1999.9639

MacFadden, A., O'Donoghue, Z., Silva, P., Chapman, E. G., Olsthoorn, R. C., Sterken, M. G., et al. (2018). Mechanism and structural diversity of exoribonuclease-resistant RNA structures in flaviviral RNAs. Nat. Commun. 9:119. doi: 10.1038/s41467-017-02604-y

Mackenzie, J. M., Khromykh, A. A., Jones, M. K., and Westaway, E. G. (1998). Subcellular localization and some biochemical properties of the flavivirus Kunjin nonstructural proteins NS2A and NS4A. Virology 245, 203-215. doi: 10.1006/viro.1998.9156

Maines, T. R., Young, M., Dinh, N. N., and Brinton, M. A. (2005). Two cellular proteins that interact with a stem loop in the simian hemorrhagic fever virus $3^{\prime}$ (+)NCR RNA. Virus Res. 109, 109-124. doi: 10.1016/j.virusres.2004.11.014

Manokaran, G., Finol, E., Wang, C., Gunaratne, J., Bahl, J., Ong, E. Z., et al. (2015). Dengue subgenomic RNA binds TRIM25 to inhibit interferon expression for epidemiological fitness. Science 350, 217-221. doi: 10.1126/science.aab3369

Manzano, M., Reichert, E. D., Polo, S., Falgout, B., Kasprzak, W., Shapiro, B. A., et al. (2011). Identification of cis-acting elements in the $3^{\prime}$-untranslated region of the dengue virus type 2 RNA that modulate translation and replication. J. Biol. Chem. 286, 22521-22534. doi: 10.1074/jbc.M111.234302

Matsuda, D., and Dreher, T. W. (2004). The tRNA-like structure of Turnip yellow mosaic virus RNA is a $3^{\prime}$-translational enhancer. Virology $321,36-46$. doi: $10.1016 /$ j.virol.2003.10.023

Mazan-Mamczarz, K., Lal, A., Martindale, J. L., Kawai, T., and Gorospe, M. (2006). Translational repression by RNA-binding protein TIAR. Mol. Cell. Biol. 26, 2716-2727. doi: 10.1128/MCB.26.7.2716-2727.2006

Michalski, D., Ontiveros, J. G., Russo, J., Charley, P. A., Anderson, J. R., Heck, A. M., et al. (2019). Zika virus noncoding sfRNAs sequester multiple hostderived RNA-binding proteins and modulate mRNA decay and splicing during infection. J. Biol. Chem. 294, 16282-16296. doi: 10.1074/jbc.RA119.00 9129

Modrow, S., Falke, D., Truyen, U., and Schätzl, H. (2013). "Viruses with singlestranded, positive-sense RNA genomes," in Molecular Virology, eds S. Modrow,
D. Falke, U. Truyen, and H. Schätzl (Berlin; Heidelberg: Springer), 185-349. doi: 10.1007/978-3-642-20718-1_14

Moes, L., and Wirth, M. (2007). The internal initiation of translation in bovine viral diarrhea virus RNA depends on the presence of an RNA pseudoknot upstream of the initiation codon. Virol. J. 4:124. doi: 10.1186/1743-422X-4-124

Moon, S. L., Anderson, J. R., Kumagai, Y., Wilusz, C. J., Akira, S., Khromykh, A. A., et al. (2012). A noncoding RNA produced by arthropod-borne flaviviruses inhibits the cellular exoribonuclease XRN1 and alters host mRNA stability. RNA 18, 2029-2040. doi: 10.1261/rna.034330.112

Nadar, M., Chan, M. Y., Huang, S. W., Huang, C. C., Tseng, J. T., and Tsai, C. H. (2011). HuR binding to AU-rich elements present in the $3^{\prime}$ untranslated region of Classical swine fever virus. Virol. J. 8:340. doi: 10.1186/1743-422X-8-340

Nanda, S. K., Johnson, R. F., Liu, Q., and Leibowitz, J. L. (2004). Mitochondrial HSP70, HSP40, and HSP60 bind to the $3^{\prime}$ untranslated region of the murine hepatitis virus genome. Arch. Virol. 149, 93-111. doi: 10.1007/s00705-003-0196-4

Nanda, S. K., and Leibowitz, J. L. (2001). Mitochondrial aconitase binds to the $3^{\prime}$ untranslated region of the mouse hepatitis virus genome. J. Virol. 75, 3352-3362. doi: 10.1128/JVI.75.7.3352-3362.2001

Narayanan, K., and Makino, S. (2013). Interplay between viruses and host mRNA degradation. Biochim. Biophys. Acta 1829, 732-741. doi: 10.1016/j.bbagrm.2012.12.003

Nicholson, B. L., and White, K. A. (2014). Functional long-range RNA-RNA interactions in positive-strand RNA viruses. Nat. Rev. Microbiol. 12, 493-504. doi: $10.1038 /$ nrmicro3288

Ochsenreiter, R., Hofacker, I. L., and Wolfinger, M. T. (2019). Functional RNA structures in the $3^{\prime}$ UTR of tick-borne, insect-specific and no-known-vector flaviviruses. Viruses 11:298. doi: 10.3390/v11030298

Ogram, S. A., Spear, A., Sharma, N., and Flanegan, J. B. (2010). The 5' CL-PCBP RNP complex, $3^{\prime}$ poly (A) tail and $2 \mathrm{~A}$ pro are required for optimal translation of poliovirus RNA. Virology 397, 14-22. doi: 10.1016/j.virol.2009.11.006

Olson, K. E., and Blair, C. D. (2015). Arbovirus-mosquito interactions: RNAi pathway. Curr. Opin. Virol. 15, 119-126. doi: 10.1016/j.coviro.2015.10.001

Olsthoorn, R., and Bol, J. F. (2001). Sequence comparison and secondary structure analysis of the $3^{\prime}$ noncoding region of flavivirus genomes reveals multiple pseudoknots. RNA 7, 1370-1377. doi: 10.1017/S1355838201010068

Osman, T., and Buck, K. (2003). Identification of a region of the tobacco mosaic virus 126-and 183-kilodalton replication proteins which binds specifically to the viral $3^{\prime}$-terminal tRNA-like structure. J. Virol. 77, 8669-8675. doi: 10.1128/JVI.77.16.8669-8675.2003

Ou, X., Mao, S., Cao, J., Cheng, A., Wang, M., Zhu, D., et al. (2017). Comparative analysis of virus-host interactions caused by a virulent and an attenuated duck hepatitis A virus genotype 1. PLoS ONE 12:e0178993. doi: 10.1371/journal.pone. 0178993

Ou, X., Wang, M., Mao, S., Cao, J., Cheng, A., Zhu, D., et al. (2018). Incompatible translation drives a convergent evolution and viral attenuation during the development of live attenuated vaccine. Front. Cell. Infect. Microbiol. 8:249. doi: $10.3389 /$ fcimb.2018.00249

Paranjape, S. M., and Harris, E. (2007). Y box-binding protein-1 binds to the dengue virus $3^{\prime}$-untranslated region and mediates antiviral effects. J. Biol. Chem. 282, 30497-30508. doi: 10.1074/jbc.M705755200

Pasternak, A. O., Spaan, W. J., and Snijder, E. J. (2006). Nidovirus transcription: how to make sense... ? J. Gen. Virol. 87, 1403-1421. doi: 10.1099/vir.0.81611-0

Paul, D., and Bartenschlager, R. (2013). Architecture and biogenesis of plus-strand RNA virus replication factories. World J. Virol. 2:32. doi: 10.5501/wjv.v2.i2.32

Perera, R., Daijogo, S., Walter, B. L., Nguyen, J. H., and Semler, B. L. (2007). Cellular protein modification by poliovirus: the two faces of poly(rC)-binding protein. J. Virol. 81, 8919-8932. doi: 10.1128/JVI.01013-07

Pijlman, G. P., Funk, A., Kondratieva, N., Leung, J., Torres, S., van der Aa, L., et al. (2008). A highly structured, nuclease-resistant, noncoding RNA produced by flaviviruses is required for pathogenicity. Cell Host Microbe 4, 579-591. doi: 10.1016/j.chom.2008.10.007

Polacek, C., Foley, J. E., and Harris, E. (2009a). Conformational changes in the solution structure of the dengue virus $5^{\prime}$ end in the presence and absence of the $3^{\prime}$ untranslated region. J. Virol. 83, 1161-1166. doi: 10.1128/JVI.01362-08

Polacek, C., Friebe, P., and Harris, E. (2009b). Poly (A)-binding protein binds to the non-polyadenylated $3^{\prime}$ untranslated region of dengue virus and modulates translation efficiency. J. Gen. Virol. 90, 687-692. doi: 10.1099/vir.0.007021-0 
Pompon, J., Manuel, M., Ng, G. K., Wong, B., Shan, C., Manokaran, G., et al. (2017). Dengue subgenomic flaviviral RNA disrupts immunity in mosquito salivary glands to increase virus transmission. PLoS Pathog. 13:e1006535. doi: 10.1371/journal.ppat.1006535

Rodríguez-Pulido, M., Borrego, B., Sobrino, F., and Sáiz, M. (2011). RNA structural domains in noncoding regions of the foot-and-mouth disease virus genome trigger innate immunity in porcine cells and mice. J. Virol. 85, 6492-6501. doi: 10.1128/JVI.00599-11

Romero, T. A., Tumban, E., Jun, J., Lott, W. B., and Hanley, K. A. (2006). Secondary structure of dengue virus type $43^{\prime}$ untranslated region: impact of deletion and substitution mutations. J. Gen. Virol. 87, 3291-3296. doi: 10.1099/vir.0.82182-0

Saito, T., Owen, D. M., Jiang, F., Marcotrigiano, J., and Gale, M., Jr. (2008). Innate immunity induced by composition-dependent RIG-I recognition of hepatitis $\mathrm{C}$ virus RNA. Nature 454, 523-527. doi: 10.1038/nature07106

Sakai, M., Muto, M., Hirano, M., Kariwa, H., and Yoshii, K. (2015). Virulence of tick-borne encephalitis virus is associated with intact conformational viral RNA structures in the variable region of the $3^{\prime}$-UTR. Virus Res. 203, 36-40. doi: 10.1016/j.virusres.2015.03.006

Sakai, M., Yoshii, K., Sunden, Y., Yokozawa, K., Hirano, M., and Kariwa, H. (2014). Variable region of the $3^{\prime}$ UTR is a critical virulence factor in the far-eastern subtype of tick-borne encephalitis virus in a mouse model. J. Gen. Virol. $95(\mathrm{Pt}$ 4), 823-835. doi: 10.1099/vir.0.060046-0

Scheel, T. K., Luna, J. M., Liniger, M., Nishiuchi, E., Rozen-Gagnon, K., Shlomai, A., et al. (2016). A broad RNA virus survey reveals both miRNA dependence and functional sequestration. Cell Host Microbe 19, 409-423. doi: 10.1016/j.chom.2016.02.007

Scheller, N., Mina, L. B., Galão, R. P., Chari, A., Giménez-Barcons, M., Noueiry, A., et al. (2009). Translation and replication of hepatitis $C$ virus genomic RNA depends on ancient cellular proteins that control mRNA fates. Proc. Natl. Acad. Sci. U.S.A. 106, 13517-13522. doi: 10.1073/pnas.0906413106

Schnell, G., Loo, Y.-M., Marcotrigiano, J., and Gale, M., Jr. (2012). Uridine composition of the poly-U/UC tract of HCV RNA defines non-self recognition by RIG-I. PLoS Pathog. 8:e1002839. doi: 10.1371/journal.ppat.1002839

Schnettler, E., Sterken, M. G., Leung, J. Y., Metz, S. W., Geertsema, C., Goldbach, R. W., et al. (2012). Noncoding flavivirus RNA displays RNA interference suppressor activity in insect and Mammalian cells. J. Virol. 86, 13486-13500. doi: 10.1128/JVI.01104-12

Schnettler, E., Tykalová, H., Watson, M., Sharma, M., Sterken, M. G., Obbard, D. J., et al. (2014). Induction and suppression of tick cell antiviral RNAi responses by tick-borne flaviviruses. Nucleic Acids Res. 42, 9436-9446. doi: 10.1093/nar/gku657

Schuessler, A., Funk, A., Lazear, H. M., Cooper, D. A., Torres, S., Daffis, S., et al. (2012). West Nile virus noncoding subgenomic RNA contributes to viral evasion of the type I interferon-mediated antiviral response. J. Virol. 86, 5708-5718. doi: 10.1128/JVI.00207-12

Sheng, C., Chen, Y., Xiao, J., Xiao, J., Wang, J., Li, G., et al. (2012). Classical swine fever virus NS5A protein interacts with $3^{\prime}$-untranslated region and regulates viral RNA synthesis. Virus Res. 163, 636-643. doi: $10.1016 /$ j.virusres.2012.01.004

Sheng, C., Xiao, M., Geng, X., Liu, J., Wang, Y., and Gu, F. (2007). Characterization of interaction of classical swine fever virus NS3 helicase with $3^{\prime}$ untranslated region. Virus Res. 129, 43-53. doi: 10.1016/j.virusres.2007.05.004

Sheng, C., Zhu, Z., Yu, J., Wan, L., Wang, Y., Chen, J., et al. (2010). Characterization of NS3, NS5A and NS5B of classical swine fever virus through mutation and complementation analysis. Vet. Microbiol. 140, 72-80. doi: 10.1016/j.vetmic.2009.07.026

Shetty, S., Kim, S., Shimakami, T., Lemon, S. M., and Mihailescu, M.-R. (2010). Hepatitis $\mathrm{C}$ virus genomic RNA dimerization is mediated via a kissing complex intermediate. RNA 16, 913-925. doi: 10.1261/rna.1960410

Shwetha, S., Kumar, A., Mullick, R., Vasudevan, D., Mukherjee, N., and Das, S. (2015). HuR displaces polypyrimidine tract binding protein to facilitate la binding to the $3^{\prime}$ untranslated region and enhances hepatitis $\mathrm{C}$ virus replication. J. Virol. 89, 11356-11371. doi: 10.1128/JVI.01714-15

Silva, P. A., Molenkamp, R., Dalebout, T. J., Charlier, N., Neyts, J. H., Spaan, W. J., et al. (2007). Conservation of the pentanucleotide motif at the top of the yellow fever virus 17D $3^{\prime}$ stem-loop structure is not required for replication. J. Gen. Virol. 88, 1738-1747. doi: 10.1099/vir.0.82811-0
Silva, P. A., Pereira, C. F., Dalebout, T. J., Spaan, W. J., and Bredenbeek, P. J. (2010). An RNA pseudoknot is required for production of yellow fever virus subgenomic RNA by the host nuclease XRN1. J. Virol. 84, 11395-11406. doi: 10.1128/JVI.01047-10

Spångberg, K., Wiklund, L., and Schwartz, S. (2000). HuR, a protein implicated in oncogene and growth factor mRNA decay, binds to the $3^{\prime}$ ends of hepatitis C virus RNA of both polarities. Virology 274, 378-390. doi: 10.1006/viro.2000.0461

Spangberg, K., Wiklund, L., and Schwartz, S. (2001). Binding of the la autoantigen to the hepatitis $\mathrm{C}$ virus $3^{\prime}$ untranslated region protects the RNA from rapid degradation in vitro. J. Gen. Virol. 82, 113-120. doi: 10.1099/0022-1317-82-1-113

Sun, D., Chen, S., Cheng, A., and Wang, M. (2016). Roles of the picornaviral $3 \mathrm{C}$ proteinase in the viral life cycle and host cells. Viruses 8:82. doi: $10.3390 / \mathrm{v} 8030082$

Sun, D., Wang, M., Wen, X., Cheng, A., Jia, R., Sun, K., et al. (2017). Cleavage of poly(A)-binding protein by duck hepatitis A virus 3C protease. Sci. Rep. 7:16261. doi: 10.1038/s41598-017-16484-1

Suthar, M. S., Diamond, M. S., and Gale, M., Jr. (2013). West Nile virus infection and immunity. Nat. Rev. Microbiol. 11, 115-128. doi: 10.1038/nrmicro2950

Suzuki, R., Fayzulin, R., Frolov, I., and Mason, P. W. (2008). Identification of mutated cyclization sequences that permit efficient replication of West Nile virus genomes: use in safer propagation of a novel vaccine candidate. J. Virol. 82, 6942-6951. doi: 10.1128/JVI.00662-08

Sztuba-Solinska, J., Teramoto, T., Rausch, J. W., Shapiro, B. A., Padmanabhan, R., and Le Grice, S. F. (2013). Structural complexity of dengue virus untranslated regions: cis-acting RNA motifs and pseudoknot interactions modulating functionality of the viral genome. Nucleic Acids Res. 41, 5075-5089. doi: $10.1093 /$ nar/gkt203

Ta, M., and Vrati, S. (2000). Mov34 protein from mouse brain interacts with the $3^{\prime}$ noncoding region of Japanese encephalitis virus. J. Virol. 74, 5108-5115. doi: 10.1128/JVI.74.11.5108-5115.2000

Thorne, L. G., and Goodfellow, I. G. (2014). Norovirus gene expression and replication. J. Gen. Virol. 95(Pt 2), 278-291. doi: 10.1099/vir.0.059634-0

Tilgner, M., Deas, T. S., and Shi, P.-Y. (2005). The flavivirus-conserved pentanucleotide in the $3^{\prime}$ stem-loop of the West Nile virus genome requires a specific sequence and structure for RNA synthesis, but not for viral translation. Virology 331, 375-386. doi: 10.1016/j.virol.2004.07.022

Tingting, P., Caiyun, F., Zhigang, Y., Pengyuan, Y., and Zhenghong, Y. (2006). Subproteomic analysis of the cellular proteins associated with the $3^{\prime}$ untranslated region of the hepatitis $\mathrm{C}$ virus genome in human liver cells. Biochem. Biophys. Res. Commun. 347, 683-691. doi: 10.1016/j.bbrc.2006.06.144

Trobaugh, D. W., Gardner, C. L., Sun, C., Haddow, A. D., Wang, E., Chapnik, E., et al. (2014). RNA viruses can hijack vertebrate microRNAs to suppress innate immunity. Nature 506, 245-248. doi: 10.1038/nature12869

Trobaugh, D. W., Sun, C., Bhalla, N., Gardner, C. L., Dunn, M. D., and Klimstra, W. B. (2019). Cooperativity between the $3^{\prime}$ untranslated region microRNA binding sites is critical for the virulence of eastern equine encephalitis virus. PLoS Pathog. 15:e1007867. doi: 10.1371/journal.ppat.1007867

Vashist, S., Anantpadma, M., Sharma, H., and Vrati, S. (2009). La protein binds the predicted loop structures in the $3^{\prime}$ non-coding region of Japanese encephalitis virus genome: role in virus replication. J Gen. Virol. 90(Pt 6), 1343-1352. doi: 10.1099/vir.0.010850-0

Vashist, S., Bhullar, D., and Vrati, S. (2011). La protein can simultaneously bind to both $3^{\prime}$ - and $5^{\prime}$-noncoding regions of Japanese encephalitis virus genome. DNA Cell Biol. 30, 339-346. doi: 10.1089/dna.2010.1114

Verheije, M., Olsthoorn, R., Kroese, M., Rottier, P., and Meulenberg, J. (2002). Kissing interaction between $3^{\prime}$ noncoding and coding sequences is essential for porcine arterivirus RNA replication. J. Virol. 76, 1521-1526. doi: 10.1128/JVI.76.3.1521-1526.2002

Verma, B., Bhattacharyya, S., and Das, S. (2010). Polypyrimidine tract-binding protein interacts with coxsackievirus B3 RNA and influences its translation. J. Gen. Virol. 91, 1245-1255. doi: 10.1099/vir.0.018507-0

Villordo, S. M., Filomatori, C. V., Sánchez-Vargas, I., Blair, C. D., and Gamarnik, A. V. (2015). Dengue virus RNA structure specialization facilitates host adaptation. PLoS Pathog. 11:e1004604. doi: 10.1371/journal.ppat.10 04604 
Villordo, S. M., and Gamarnik, A. V. (2009). Genome cyclization as strategy for flavivirus RNA replication. Virus Res. 139, 230-239. doi: 10.1016/j.virusres.2008.07.016

Villordo, S. M., and Gamarnik, A. V. (2013). Differential RNA sequence requirement for dengue virus replication in mosquito and mammalian cells. J. Virol. 87, 9365-9372. doi: 10.1128/JVI.00567-13

Waggoner, S., and Sarnow, P. (1998). Viral ribonucleoprotein complex formation and nucleolar-cytoplasmic relocalization of nucleolin in poliovirus-infected cells. J. Virol. 72, 6699-6709. doi: 10.1128/JVI.72.8.6699-6709.1998

Ward, A. M., Bidet, K., Yinglin, A., Ler, S. G., Hogue, K., Blackstock, W., et al. (2011). Quantitative mass spectrometry of DENV-2 RNA-interacting proteins reveals that the DEAD-box RNA helicase DDX6 binds the DB1 and DB2 $3^{\prime}$ UTR structures. RNA Biol. 8, 1173-1186. doi: 10.4161/rna.8.6.17836

Wei, Y., Qin, C., Jiang, T., Li, X., Zhao, H., Liu, Z., et al. (2009). Translational regulation by the $3^{\prime}$ untranslated region of the dengue type 2 virus genome. Am. J. Trop. Med. Hyg. 81, 817-824. doi: 10.4269/ajtmh.2009.08-0595

Wen, X., Guo, J., Sun, D., Wang, M., Cao, D., Cheng, A., et al. (2019). Mutations in VP0 and 2C proteins of duck hepatitis A virus type 3 attenuate viral infection and virulence. Vaccines 7:111. doi: 10.3390/vaccines7030111

Wong, J., Si, X., Angeles, A., Zhang, J., Shi, J., Fung, G., et al. (2013). Cytoplasmic redistribution and cleavage of AUF1 during coxsackievirus infection enhance the stability of its viral genome. FASEB J. 27, 2777-2787. doi: 10.1096/fj.12-226498

Wood, J., Frederickson, R. M., Fields, S., and Patel, A. H. (2001). Hepatitis C virus $3^{\prime} \mathrm{X}$ region interacts with human ribosomal proteins. J. Virol. 75, 1348-1358. doi: 10.1128/JVI.75.3.1348-1358.2001

Xie, X., Zou, J., Zhang, X., Zhou, Y., Routh, A. L., Kang, C., et al. (2019). Dengue NS2A protein orchestrates virus assembly. Cell Host Microbe 26, 606-622.e608. doi: 10.1016/j.chom.2019.09.015

Yocupicio-Monroy, M., Padmanabhan, R., Medina, F., and del Angel, R. M. (2007). Mosquito la protein binds to the $3^{\prime}$ untranslated region of the positive and negative polarity dengue virus RNAs and relocates to the cytoplasm of infected cells. Virology 357, 29-40. doi: 10.1016/j.virol.2006.07.042

Yocupicio-Monroy, R. M. E., Medina, F., Reyes-del Valle, J., and del Angel, R. M. (2003). Cellular proteins from human monocytes bind to dengue
4 virus minus-strand $3^{\prime}$ untranslated region RNA. J. Virol. 77, 3067-3076. doi: 10.1128/JVI.77.5.3067-3076.2003

You, S., and Rice, C. M. (2008). 3' RNA elements in hepatitis C virus replication: kissing partners and long poly (U). J. Virol. 82, 184-195. doi: 10.1128/JVI.01796-07

Yu, K. L., Jang, S. I., and You, J. C. (2009). Identification of in vivo interaction between Hepatitis C Virus core protein and 5' and 3' UTR RNA. Virus Res. 145 285-292. doi: 10.1016/j.virusres.2009.07.023

Yu, Z., Qianda, C., Mingshu, W., Renyong, J., Shun, C., Dekang, Z., et al. (2017). The 3D protein of duck hepatitis A virus type 1 binds to a viral genomic $3^{\prime}$ UTR and shows RNA-dependent RNA polymerase activity. Virus genes 53, 831-839. doi: 10.1007/s11262-017-1476-5

Zeenko, V., and Gallie, D. R. (2005). Cap-independent translation of tobacco etch virus is conferred by an RNA pseudoknot in the $5^{\prime}$-leader. J. Biol. Chem. 280, 26813-26824. doi: 10.1074/jbc.M503576200

Zhang, B., Dong, H., Stein, D. A., Iversen, P. L., and Shi, P.-Y. (2008). West Nile virus genome cyclization and RNA replication require two pairs of long-distance RNA interactions. Virology 373, 1-13. doi: 10.1016/j.virol.2008. 01.016

Zhang, Q. Y., Li, X. F., Niu, X., Li, N., Wang, H. J., Deng, C. L., et al. (2020). Short direct repeats in the $3^{\prime}$ untranslated region are involved in subgenomic flaviviral RNA production. J. Virol. 94:e01175-19. doi: 10.1128/JVI.01175-19

Conflict of Interest: The authors declare that the research was conducted in the absence of any commercial or financial relationships that could be construed as a potential conflict of interest.

Copyright (C) 2020 Liu, Zhang, Wang, Cheng, Yang, Wu, Jia, Liu, Zhu, Chen, Zhang, Zhao, Huang, Mao, Ou, Gao, Wang, Xu, Chen, Zhu, Luo, Liu, Yu, Zhang, Tian, Pan and Chen. This is an open-access article distributed under the terms of the Creative Commons Attribution License (CC BY). The use, distribution or reproduction in other forums is permitted, provided the original author(s) and the copyright owner $(s)$ are credited and that the original publication in this journal is cited, in accordance with accepted academic practice. No use, distribution or reproduction is permitted which does not comply with these terms. 